\title{
NOX2-Dependent Reactive Oxygen Species Regulate Formyl-Peptide Receptor 1-Mediated TrkA Transactivation in SH-SY5Y Cells
}

\author{
Martina Castaldo, Cristiana Zollo, Gabriella Esposito, Rosario Ammendola (D), \\ and Fabio Cattaneo
}

Department of Molecular Medicine and Medical Biotechnology, School of Medicine, University of Naples Federico II, Naples, Italy

Correspondence should be addressed to Rosario Ammendola; rosario.ammendola@unina.it

and Fabio Cattaneo; fabio.cattaneo@unina.it

Received 11 July 2019; Revised 8 October 2019; Accepted 18 October 2019; Published 2 December 2019

Guest Editor: Antonina Luca

Copyright (c) 2019 Martina Castaldo et al. This is an open access article distributed under the Creative Commons Attribution License, which permits unrestricted use, distribution, and reproduction in any medium, provided the original work is properly cited.

\begin{abstract}
Several enzymes are capable of producing reactive oxygen species (ROS), but only NADPH oxidases (NOX) generate ROS as their primary and sole function. In the central nervous system, NOX2 is the major source of ROS, which play important roles in signalling and functions. NOX2 activation requires $47^{\text {phox }}$ phosphorylation and membrane translocation of cytosolic subunits. We demonstrate that SH-SY5Y cells express $47^{\text {phox }}$ and that the stimulation of Formyl-Peptide Receptor 1 (FPR1) by N-fMLP induces $\mathrm{p} 47^{\text {phox }}$ phosphorylation and NOX-dependent superoxide generation. FPR1 is a member of the G protein-coupled receptor (GPCR) family and is able to transphosphorylate several tyrosine kinase receptors (RTKs). This mechanism requires ROS as signalling intermediates and is necessary to share information within the cell. We show that N-fMLP stimulation induces the phosphorylation of cytosolic Y490, Y751, and Y785 residues of the neurotrophin receptor TrkA. These phosphotyrosines provide docking sites for signalling molecules which, in turn, activate Ras/MAPK, PI3K/Akt, and PLC$\gamma 1 /$ PKC intracellular cascades. N-fMLP-induced ROS generation plays a critical role in FPR1-mediated TrkA transactivation. In fact, the blockade of NOX2 functions prevents Y490, Y751, and Y785 phosphorylation, as well as the triggering of downstream signalling cascades. Moreover, we observed that FPR1 stimulation by N-fMLP also improves proliferation, cellular migration, and neurite outgrowth of SH-SY5Y cells.
\end{abstract}

\section{Introduction}

Neurotrophic factors, such as neurotrophin-nerve growth factor (NGF), brain-derived neurotrophic factor (BDNF), ciliary neurotrophic factor (CNTF), glial-derived neurotrophic factor (GDNF), and neurotrophin-3 and 4 (NT-3 and NT-4), represent a family of biomolecules necessary for neuronal survival and plasticity. They support growth and differentiation of both developing and mature neurons by binding transmembrane receptors and, in turn, stimulating protein tyrosine phosphorylations in downstream signalling cascades. Neurotrophic factors also play a key role in neurodegenerative diseases and neuropsychiatric disorders such as Bipolar Disorders (BD), depression, and eating disorders. Neurotrophins bind the tyrosine kinase receptors (RTKs) Trk; CNTF binds the CNTF receptor complex and GDNF family members signal through the tyrosine kinase receptor c-Ret [1]. NGF, BDNF, NT-3, and NT-4 also bind the p75 neurotrophin receptor $\left(\mathrm{p} 75^{\mathrm{NTR}}\right)$, a member of the TNF receptor superfamily [2], which is a potential cell death receptor and whose activity is nullified by Trk tyrosine kinase signalling $[3,4]$. Trk receptors belong to a family of three RTKs and each neurotrophin binds to a specific member of Trk family with NGF binding to TrkA, BDNF and NT-4 binding to $\operatorname{TrkB}$ and NT-3 binding to $\operatorname{TrkC}[5,6]$.

TrkA receptor activation results in phosphorylation of Y670, Y674, and Y675 localized in the activation loop of the 
kinase cytoplasmic domain, which enhances tyrosine kinase activity of the receptor [5]. Y490, Y751, and Y785 of TrkA are the main phosphorylated tyrosine residues in the juxtamembrane region, in the tyrosine kinase domain, and in the intracellular C-terminal tail, respectively [5, 7]. These phosphorylated tyrosines create docking sites for the recruitment of proteins containing PTB or SH2 domains. Phosphotyrosine 490 interacts with Shc, Frs2, and other adapter molecules, which trigger the activation of Ras/MAPK and PI3K/Akt pathways. Y751 phosphorylation is essential for PI3K docking and activation, whereas phosphorylated Y785 recruits PLC $\gamma 1$ and activates PKC $[5,7]$.

Formyl-peptide receptors (FPRs) belong to the G protein-coupled receptor (GPCR) family and are associated with pertussis toxin- (PTX-) sensitive Gi proteins [8]. Their main function is to detect the presence of noxious molecules and to drive cells till the site of release of harmful molecules. The sensing function of FPRs includes the detection of pathogens and of formylated peptides derived from mitochondrial peptides. Other endogenous ligands include the antimicrobial peptide LL-37, the anti-inflammatory lipid lipoxin A4, the proinflammatory molecule SAA, urokinase and its receptor, resolvins, beta amyloid $(\mathrm{A} \beta)_{1-42}$ peptide, prion protein $(\operatorname{Prp})_{106-126}$, humanin, neuropeptides, the dual pro- and anti-inflammatory protein annexin 1, chemokine variants, vasoactive intestinal peptide, and pituitary adenylate cyclase-activating polypeptide (PACAP) [9-16].

Human FPR1, FPR2, and FPR3 are functional members of the FPR family. FPR1 binds efficiently to the formylated peptide $\mathrm{N}$-formyl-methionyl-leucyl-phenylalanine (N-fMLP), whereas FPR2 is activated by WKYMVm peptide [17]. FPR3 does not bind to N-fMLP, and shares some nonformylated peptide ligands with FPR2 [18]. However, a set of formylated peptides have been identified as natural agonists for FPR3 [19]. FPR1 and FPR2 are expressed in several cell types [20, 21], whereas FPR3, is expressed in monocytes, dendritic cells $[8,16]$, and HUVEC cells [22]. FPR2 is also expressed on nuclear membranes of cancer cells [23], whereas FPR3 is localized within the cytoplasm [24]. Overall, binding of specific agonists to FPR1 is associated with proinflammatory responses, while FPR2 is an unusual receptor because it can convey opposite signals, depending on the ligands and on different receptor domains used by distinct agonists $[25,26]$. Endocrine cells and neurons in the central nervous system (CNS) also express FPR1 $[8,27]$, whereas neurons of the vomeronasal organ express the other members of the FPR family $[28,29]$. FPRs signalling exerts a modulatory effect on anxiety-like behaviours. In fact, $F$ pr1 ${ }^{-/-}$mice exhibit normal spatial memory and learning capacity, but reduced anxiety-like behavior, increased exploratory activity, and impaired fear memory [30]. Fpr2/3-deficient mice show increased explorative behaviour and reduced fear, as well as a distinct profile of behaviour characterized by reduced anxiety [31].

RTK transactivation mediated by GPCR agonists represents a mechanism to increase the information exchange across the entire cell and to coordinate the multitude of physiological or pathological stimuli to which a cell is exposed. Several molecular mechanisms are responsible for RTK transactivation by GPCRs. They include the activation of metalloproteases, the activation of cytosolic membraneassociated tyrosine kinases, and NADPH oxidasedependent reactive oxygen species (ROS) generation [32]. Over the last years, six homologs of the NADPH oxidase have been identified: NOX1, NOX2, NOX3, NOX4, NOX5, DUOX1, and DUOX2 and are referred as the NOX family of NADPH oxidases [33] which produces ROS as their primary and sole function. NOX2 consists of the cytosolic proteins $\mathrm{p} 47^{\text {phox }}, \mathrm{p} 67^{\text {phox }}, \mathrm{p} 40^{\text {phox }}, \mathrm{Rac} 1$, and of membranebound subunits $\mathrm{p} 22^{\text {phox }}$ and gp $91^{\text {phox }}$. In the nervous system, NOX2 is the most important source of ROS and its activation requires phosphorylation and membrane translocation of the $\mathrm{p} 47^{\text {phox }}$ subunit. In phagocytic and nonphagocytic cells, FPR stimulation by cognate agonists results in MEK- and PKCdependent $\mathrm{p} 47^{\mathrm{phox}}$ phosphorylation and, in turn, in ROS generation $[9,20,34,35]$, which act as intracellular second messengers by activating several redox signalling cascades.

In different cell types, FPR stimulation induces phosphorylation of Y951, Y996, and Y1175 residues of VEGFR2 [36] and of Y1313, Y1349, and Y1356 residues of the HGF receptor [35], as well as EGFR transactivation [37], suggesting that FPRs are able to integrate GPCR signalling with tyrosine kinase activity of RTKs even in the absence of direct stimulation by growth factors [32]. ROS play a crucial role in these cross-talk mechanisms. In fact, blockade of NADPH oxidase functions by siRNA or by specific inhibitors prevents EGFR, VEGFR2, and c-Met transphosphorylation [35-37].

Trk receptors can also be activated via GPCR stimulation without the involvement of neurotrophins [38]. In human monocytes, cross talks between FPR1, EGFR, and TrkA are essential for receptor-mediated activation and to modulate proinflammatory mediators [39]. Adenosine can activate TrkA phosphorylation through an adenosine $2 \mathrm{~A}$ receptor, a member of the GPCR family [40] and the neuropeptide PACAP, which acts through a GPCR, transactivates TrkA [41]. Furthermore, the activation of angiotensin receptor type-2 transactivates $\operatorname{TrkB}[42]$.

Herein, we show that the SH-SY5Y neuroblastoma cell line expresses NOX2 components, FPR1, and TrkA, and that FPR1 stimulation by formylated peptides induces NADPH-dependent ROS generation, as well as the phosphorylation of Y490, Y751, and Y785 residues of TrkA. Cytosolic phosphotyrosines of TrkA act as docking sites for signalling proteins that, in turn, activate Ras/MAPK, PLC- $\gamma 1 / \mathrm{PKC}$, and PI3K/Akt intracellular cascades. Furthermore, FPR1-mediated TrkA transactivation promotes cell proliferation, wound healing, and neurite outgrowth of SH-SY5Y cells.

\section{Materials and Methods}

2.1. Reagents. SH-SY5Y cell line (ATCC, Manassas, VA, USA) was cultured in Dulbecco's modified Eagle's medium (DMEM) (Thermo Fisher Scientific, Monza, Italy) containing $15 \%$ foetal bovine serum (FBS) (Invitrogen). After reaching $80 \%$ confluence, cells were serum-starved for 24 hours and stimulated with N-fMLP (Sigma) at the final concentration of $0.1 \mu \mathrm{M}$ for 2,5 , or 10 minutes. In other experiments, 
serum-deprived cells were preincubated for 16 hours with pertussis toxin (PTX) (Sigma) at a final concentration of $100 \mathrm{ng} / \mathrm{mL}$, or with $5 \mu \mathrm{M}$ cyclosporin $\mathrm{H}$ (CSH) (Sigma) for 30 minutes, or with $5 \mu \mathrm{M}$ rottlerin (Sigma) for 1 hour, or with $100 \mu \mathrm{M}$ apocynin (Sigma) for 2 hours, or with $10 \mu \mathrm{M}$ GW441756 (Sigma) for 1 hour, before the stimulation with $\mathrm{N}$-fMLP for 5 minutes. SDS-PAGE reagents were obtained from Bio-Rad (Hercules, CA, USA). Anti-phosphoAkt(S473) (cat. no. 4060), anti-phosphoP38MAPK(T180, Y182) (cat. no. 4511), anti-CD133 (cat. no. 5860), anti-phosphoTrkA(Y490) (cat. no. 9141), and anti-phosphoTrkA(Y785) (cat. no. 4168) were from Cell Signalling Technology (Danvers, MA, USA). Anti-phosphoTrkA(Y751) (cat. no. 44-1342G) was from Life Technologies. Anti-phosphop $47^{\text {phox }}$ (S359) (cat. no. GTX55429) was from GeneTex (Irvine, CA, USA). Anti-phosphoERK 1/2 (cat. no. SC-81492), anti-PKC $\alpha$ (cat. no. SC-8393), anti-PKC $\delta$ (cat. no. SC-937), anti-phosphoPKC $\delta$ (T507) (cat. no. SC-11770), anti-ERK 1/2 (cat. no. SC-514302), ant-Akt (cat. no. SC-8312), anti-TrkA (cat. no. SC-398728), anti-tubulin (cat. no. SC-8035), anti-rabbit (cat. no. SC-2357), and anti-mouse (cat. no. SC-2005) antibodies were purchased from Santa Cruz Biotechnology (Santa Cruz, CA, USA). Protein A-horseradish peroxidase was from Thermo Scientific (Little Chalfont, Buckinghamshire, UK).

2.2. Protein Extraction and Western Blot Analysis. Western blot assay was performed as previously described [43] on whole or membrane lysates. Proteins were purified from growth-arrested SH-SY5Y cells stimulated or not with $0.1 \mu \mathrm{M} \mathrm{N}$-fMLP, in the presence or absence of the appropriate amounts of selective inhibitors. Whole lysates were obtained by incubation with RIPA buffer $(50 \mathrm{mM}$ Tris- $\mathrm{HCl}$, pH 7.4, $150 \mathrm{mM} \mathrm{NaCl}, 1 \%$ NP-40, $1 \mathrm{mM}$ EDTA, $0.25 \%$ sodium deoxycholate, $1 \mathrm{mM} \mathrm{NaF}, 10 \mu \mathrm{M} \mathrm{Na}_{3} \mathrm{VO}_{4}, 1 \mathrm{mM}$ phenylmethylsulfonylfluoride (PMSF), $10 \mu \mathrm{g} / \mathrm{mL}$ aprotinin, $10 \mu \mathrm{g} / \mathrm{mL}$ pepstatin, and $10 \mu \mathrm{g} / \mathrm{mL}$ leupeptin) for $45 \mathrm{~min}$ at $4^{\circ} \mathrm{C}$ [44]. Membrane proteins were purified by incubating SH-SY5Y cells with a buffer containing $10 \mathrm{mM}$ Tris-HCl, $1 \mathrm{mM} \mathrm{CaCl}_{2}, 150 \mathrm{mM} \mathrm{NaCl}, 1 \mathrm{mM}$ phenylmethylsulfonylfuoride, $10 \mu \mathrm{g} / \mathrm{mL}$ aprotinin, $10 \mu \mathrm{g} / \mathrm{mL}$ pepstatin, and $10 \mu \mathrm{g} / \mathrm{mL}$ leupeptin (Buffer I). Samples were centrifuged at $400 \times \mathrm{g}$ for 10 minutes at $4^{\circ} \mathrm{C}$, to obtain a cytosolic (supernatant) and membrane (pellet) fraction. Membrane fraction was washed three times in Buffer I and incubated overnight at $4^{\circ} \mathrm{C}$ in constant agitation with a buffer containing $125 \mathrm{mM}$ Tris-HCl, $1 \mathrm{mM}$ PMSF, $1 \%$ Triton X-100, $10 \mu \mathrm{g} / \mathrm{mL}$ aprotinin, $10 \mu \mathrm{g} / \mathrm{mL}$ pepstatin, and $10 \mu \mathrm{g} / \mathrm{mL}$ leupeptin (Buffer II) [45]. Bio-Rad protein assay was used to determine protein concentration (Bio-Rad, Hercules, CA, USA). Equal amounts of proteins (40-60 $\mu$ g, see legends to figures) were separated on $8 \%, 10 \%$, or $12 \%$ SDS-PAGE (Bio-Rad), depending on molecular weight of analyzed protein. Proteins were electroblotted onto an immobilion-P PVDF membrane (Thermo Fisher Scientific), and aspecific binding sites were blocked by incubating membranes at room temperature with a solution of $5 \%$ nonfat dry milk in Tris-buffered saline $0.1 \%$ Tween for 1 hour. After overnight incubation at $4^{\circ} \mathrm{C}$ with primary antibodies, membranes were washed and incubated at room temperature for 1 hour with peroxidase-conjugated mouse or rabbit IgG. The expression of targeted proteins was detected by an ECL chemiluminescence reagent kit and visualized by autoradiography. A Discover Pharmacia scanner equipped with a sun spark classic densitometric workstation was used to evaluate band densitometry. The equal amount of loaded protein was determined by reprobing the same filters with an anti- $\alpha$-tubulin or anti-CD133 antibody. All western blot experiments are representative of at least four independent experiments.

2.3. Proliferation Assay. SH-SY5Y cells $\left(4 \times 10^{4}\right)$ were seeded in a 24-well plate and cultured in DMEM supplemented with $15 \%$ FBS with or without $0.1 \mu \mathrm{M}$ N-fMLP, in the presence or absence of the appropriate amounts of selective inhibitors. The number of trypan blue-positive and trypan blue-negative cells was counted at 24, 48, and 72 hours, by direct counting using Burker's chamber, as previously described [46]. Five independent experiments were performed in triplicate.

2.4. Wound Healing Assay. Wound healing assay was performed as previously described [47]. SH-SY5Y cells were cultured until $100 \%$ confluences with DMEM containing $15 \%$ FBS, at $37^{\circ} \mathrm{C}$ and $5 \% \mathrm{CO}_{2}$. The cell monolayer was scratched with an $80 \mu \mathrm{m}$ diameter sterile tip, and the plates were washed with PBS to remove the detached cells. Once the wound injury was induced, cells were serum-deprived for 24 hours and incubated with $0.1 \mu \mathrm{M}$ N-fMLP or with the vehicle, in the presence or absence of the appropriate amounts of selective inhibitors. An image was captured in the same area of the plates 0,24 , and 48 hours after the wound. Images were taken by using the Leica AF6000 Modular System and processed by using the Leica LAS AF lite software. ImageJ software was used to quantify the covered surface from four independent experiments.

2.5. Reactive Oxygen Species Assay. Generation of intracellular ROS was determined by measuring $2^{\prime}, 7^{\prime}$-dichlorodihydrofluorescein-diacetate (H2DCFDA; Sigma) oxidation into the fluorescent $2^{\prime}, 7^{\prime}$-dichlorofluorescein (DCF). Briefly, $4 \times$ $10^{4} \mathrm{SH}$-SY5Y cells were seeded in a 12-well plate and cultured at $37^{\circ} \mathrm{C}, 5 \% \mathrm{CO}_{2}$ with DMEM supplemented with $15 \%$ FBS. Cells were then serum-deprived for 24 hours and stimulated for different times with $0.1 \mu \mathrm{M} \mathrm{N}$-fMLP in the presence or absence of the appropriate amounts of selective inhibitors. Cells were then incubated for 45 minutes at $37^{\circ} \mathrm{C}$ with $50 \mu \mathrm{M}$ H2DCFDA, and the oxidization to the fluorescent DCF was analyzed on the FACS flow cytometer BD Biosciences Accuri C6 Flow Cytometer (BD Biosciences). Five independent experiments were performed in triplicate.

2.6. Neurite Outgrowth Assay. Neurite formation was determined by plating $10^{4}$ cells into wells of 12 -well plates in triplicate and cultured with DMEM supplemented with 15\% FBS. Cells were then incubated with $0.1 \mu \mathrm{M} \mathrm{N}$-fMLP or with $100 \mathrm{ng} / \mathrm{mL}$ NGF for increasing times. Five images/well were recorded and analyzed for neurite elongation after 24, 48, and 72 hours using ImageJ software plugin NeuronJ from five 
independent experiments. The length of neurites was measured starting from the soma in each area. Untreated cells were used as controls. The morphometric analysis was performed on the images obtained under inverted-phasecontrast microscopy (Leica AF6000 Modular System) and processed by using the Leica LAS AF light software.

2.7. Statistical Analysis. All the data presented are expressed as mean \pm standard error mean (SEM) and are representative of three or more independent experiments. For the statistical analyses, the comparisons were made by two-way analysis of variance (ANOVA). Differences were considered significant at a value of $p<0.05$. All the analyses were performed with GraphPad Prism version 7 (GraphPad Softweare, San Diego, CA, USA).

\section{Results and Discussion}

3.1. FPR1 Stimulation by N-fMLP Induces NOX2 Activation in SH-SY5Y Cells. The human neuroblastoma SH-SY5Y cell line is characterized by a catecholaminergic phenotype, since it can synthesize both dopamine and noradrenaline [48] and represents an in vitro model widely used in neuropsychiatric research [48-50]. NOX2 is expressed in SH-SY5Y cells [51, 52], as well as in the brain, in the microglia, astrocytes, and neurons [33], which also express NOX1 and NOX4 [33]. Induction of neuronal apoptosis in response to the brainderived neurotrophic factor is mediated by NOX2 [53], which is also involved in long-term potentiation and learning $[54,55]$ and in NMDA receptor signalling [56]. Learning and memory are impaired in NOX2 and $\mathrm{p} 47^{\text {phox }}$ knockout mice [57]. Furthermore, there is evidence for a role of microglial NOX2 in inflammatory neurodegeneration $[58,59]$ and in the injury of the nervous system, as demonstrated by the observation that NOX2 inhibition or knockdown improves the outcome of the spinal cord injury model in mice [60]. FPR-mediated NADPH oxidase-dependent ROS generation results also involved in the progression of Alzheimer's disease, mainly due to the activation of redox-sensitive pathways [61]. NOX2 activation requires $\mathrm{p} 47^{\text {phox }}$ phosphorylation and its membrane translocation $[33,62]$.

We observed that, in SH-SY5Y cells, N-fMLP induces time-dependent phosphorylation of $\mathrm{p} 47^{\text {phox }}$ within the first $5 \mathrm{~min}$, which decreases after $10 \mathrm{~min}$ of stimulation (Figure 1(a)). SH-SY5Y cells were also treated with PTX, which ADP-ribosylates Gi alpha subunit conjugated to FPR1, or with cyclosporin $\mathrm{H}$, a competitive antagonist of FPR1. The results show that $\mathrm{p} 47^{\text {phox }}$ phosphorylation is completely prevented by preincubation with PTX, or cyclosporin H (Figure 1(b)), suggesting that FPR1 is crucially involved in NADPH oxidase activation. Pretreatment with apocynin (Figure 1(c)), which prevents serine phosphorylation of $\mathrm{p} 47^{\mathrm{phox}}$ and, in turn, NADPH oxidase activation, significantly reduces $\mathrm{p} 47^{\text {phox }}$ phosphorylation. Accordingly, stimulation for different times with N-fMLP induces NOX2-dependent ROS generation with a maximum of ROS production occurring at $5 \mathrm{~min}$ (Figure 1(d)) which is prevented by preincubation with PTX, or ciclosporin $\mathrm{H}$, or apocynin (Figure $1(\mathrm{e})$ ).
3.2. FPR1 Stimulation by a Formylated Peptide Induces NOX2-Dependent TrkA Transactivation. Survival of sympathetic and sensory neurons, axon growth and synapse formation, neurotransmitter and neuropeptide synthesis [63] are mediated by NGF which binds TrkA and induces its homodimerization followed by autophosphorylation of each monomer. The NPXY and the YLDIG motif, located in the juxtamembrane region and in the C-terminus of TrkA, respectively, are then phosphorylated creating docking sited for signalling molecules [64]. Y490, Y751, and Y785 represent the main phosphotyrosine residues of TrkA in the juxtamembrane, in the tyrosine kinase, and in the intracellular Cterminal domains, respectively $[5,7]$.

Cross-communication between GPCRs and RTKs provides the connection between the wide variety of GPCRs and the strong signalling ability of RTKs to modulate intracellular pathways involved in many biological functions. SH-SY5Y cells express both FPR1 [65] and TrkA [66] receptors. We analyzed FPR1-mediated TrkA transactivation in these cells, and in time-course experiments, we observed that the incubation with $0.1 \mu \mathrm{M} \mathrm{N}$-fMLP elicits the phosphorylation of Y490, Y751, and Y785 residues of TrkA with the highest levels of phosphorylation occurring at 5 min (Figure 2(a)). Preincubation of SH-SY5Y cells with PTX or with cyclosporin $\mathrm{H}$, before the incubation with $\mathrm{N}$ fMLP, completely prevents tyrosine phosphorylation of TrkA (Figure 2(b)), strongly suggesting that TrkA transphosphorylation depends on FPR1 activation. ROS play an important role in RTK transactivation since they can inactivate, by oxidation, cysteines positioned in the catalytic site of protein tyrosine phosphatases (PTPs) [35, 36, 67]. Prevention of PTP action promotes the phosphorylated state of a RTK and, in turn, its transactivation. Several PTPs, such as NEAP/DUSP26, MEG2, SHP-1, are associated with TrkA [68-70]. We preincubated SH-SY5Y cells with apocynin before FPR1 stimulation, and we observed that N-fMLP-induced phosphorylation of Y490, Y751, and Y780 residues of TrkA is prevented (Figure 2(c)). Incubation of SH-SY5Y cells with PTX, or cyclosporin $\mathrm{H}$, or apocynin, without N-fMLP stimulation, for the same times, does not affect the expression levels of TrkA (Supplementary Figure 1). These results demonstrate that NOX2-dependent ROS generation mediates the cross-talk between FPR1 and TrkA. RTK transphosphorylation can also occur via metalloproteasemediated proteolytic cleavage of a pro-ligand, which generates a ligand able to bind and to transactivate an RTK. We cannot exclude that N-fMLP can promote the release of NGF via the activation of metalloproteases.

3.3. FPR1-Induced TrkA Transactivation Triggers the Ras/MAPK Pathway. Phosphorylated tyrosine 490 of TrkA provides a docking site for the Shc domain. A phosphotyrosine site on Shc recruits Grb2, which is bound to the exchange factor SOS that represents a scaffold for Ras. Activation of Ras is essential for neuronal differentiation, as well as for promoting survival of neuronal subpopulations [71], and is promoted by neurotrophin-dependent phosphorylation of RasGRF1 [72]. Active Ras triggers intracellular signalling through cRaf, PI3 kinase (PI3K), 


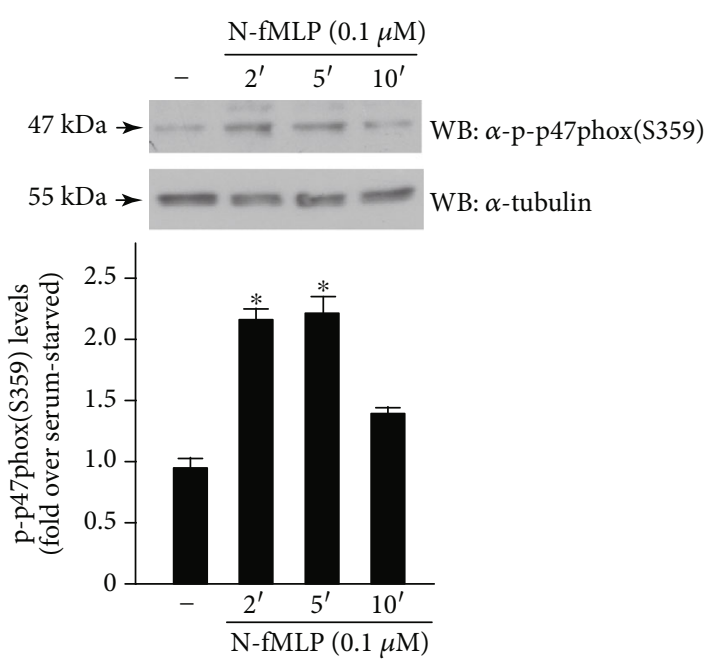

(a)

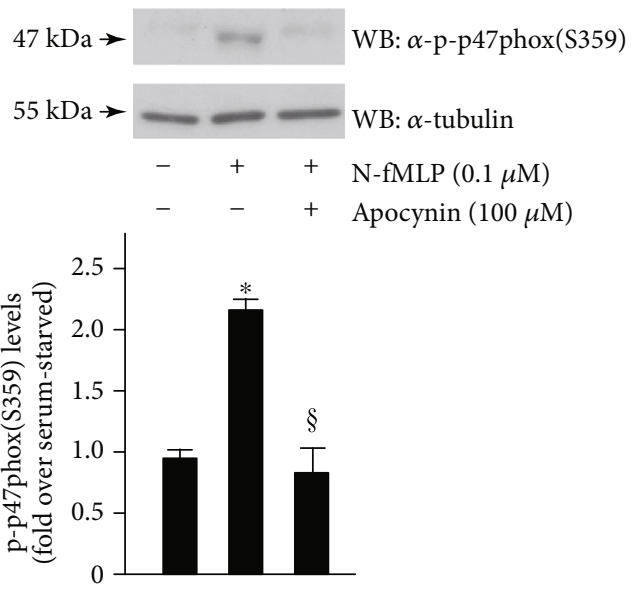

(c)
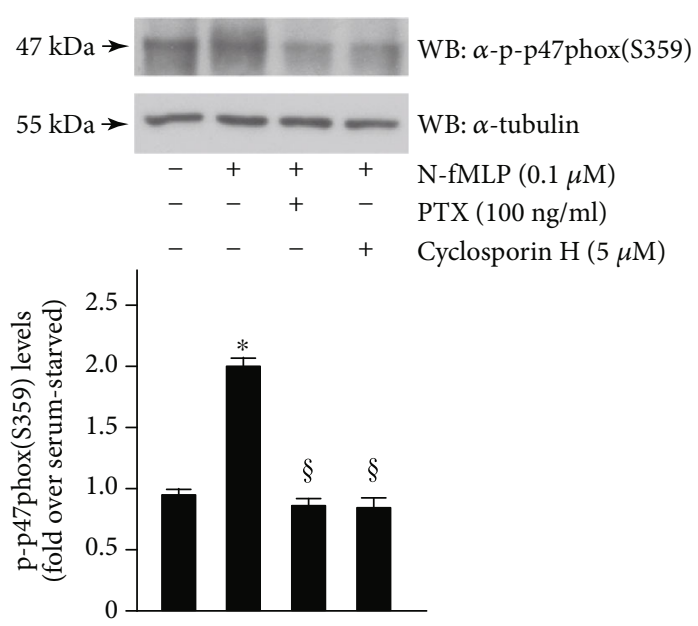

(b)

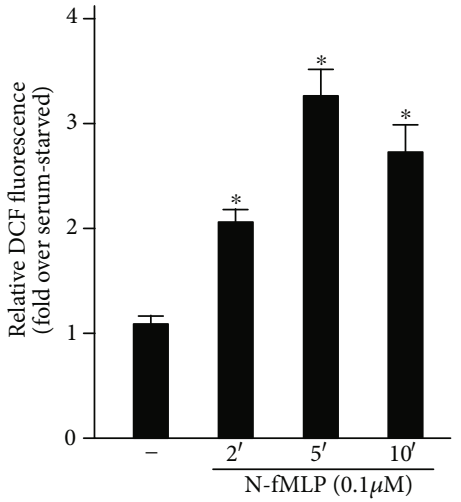

(d)

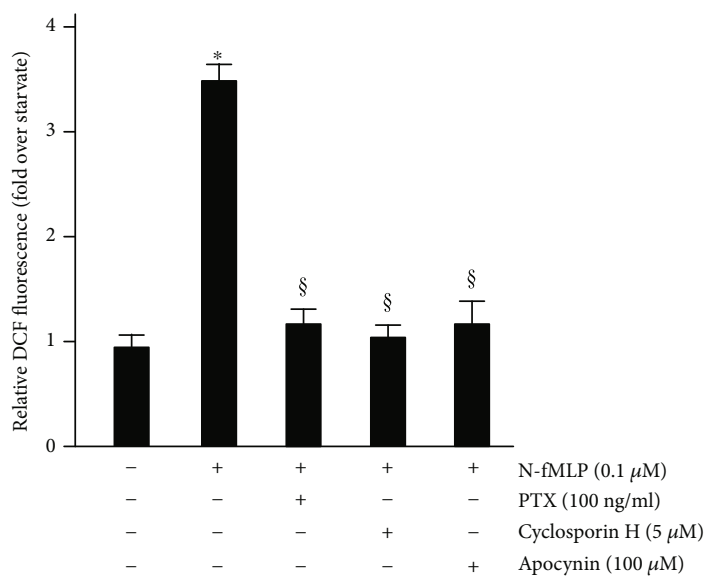

(e)

FIgURE 1: FPR1 stimulation induces NOX2 activation. SH-SY5Y cells were serum-starved for 24 hours and (a) stimulated for 2, 5, or 10 minutes with $0.1 \mu \mathrm{M} \mathrm{N}$-fMLP or (b) preincubated with $100 \mathrm{ng} / \mathrm{mL}$ PTX, or with $5 \mu \mathrm{M}$ cyclosporin $\mathrm{H}$, or (c) with $100 \mu \mathrm{M}$ apocynin before the stimulation for 5 minutes with $0.1 \mu \mathrm{M}$ N-fMLP. Sixty micrograms of whole lysates (a, b, and c) was incubated with a phospho$\mathrm{p} 47^{\text {phox }}(\mathrm{S} 359)$-specific antibody $\left(\alpha\right.$-p-p4 $\left.7^{\text {phox }}(\mathrm{S} 359)\right)$, and an anti-tubulin ( $\alpha$-tubulin) antibody was used as a control for protein loading. Band densitometry was evaluated through a scanner equipped with a densitometric workstation. Serum-starved SH-SY5Y cells were (d) stimulated with N-fMLP for increasing time or (e) preincubated with PTX, or cyclosporin H, or apocynin before the stimulation with $0.1 \mu \mathrm{M}$ N-fMLP for 5 minutes. Detection of ROS was determined by measuring the level of DCF. ${ }^{*} p<0.05$ compared to unstimulated cells. ${ }^{\circledR} p<0.05$ compared to N-fMLP stimulated cells. 


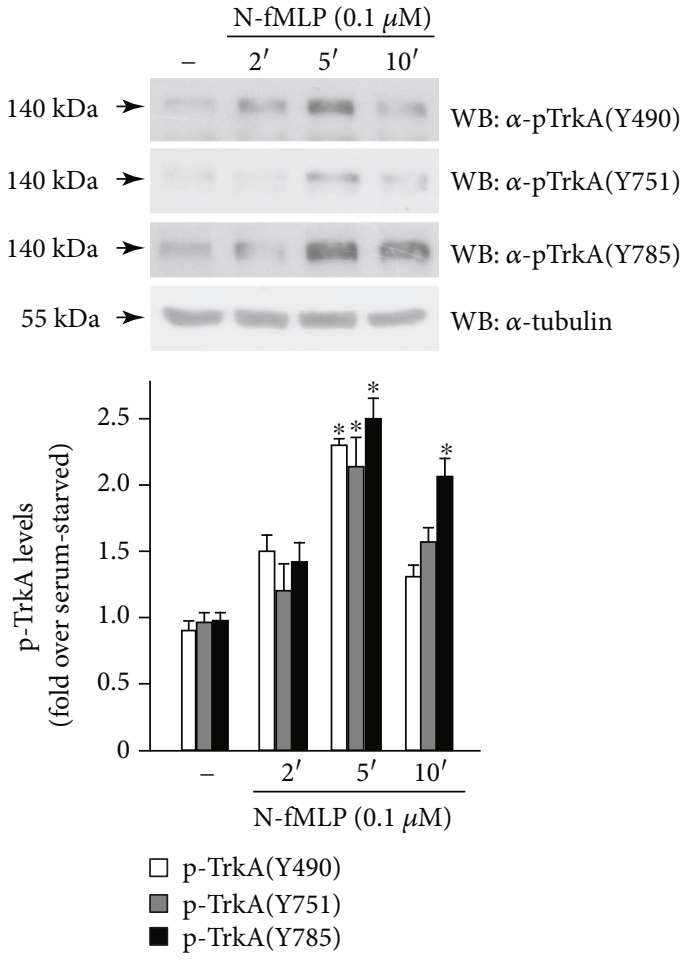

(a)
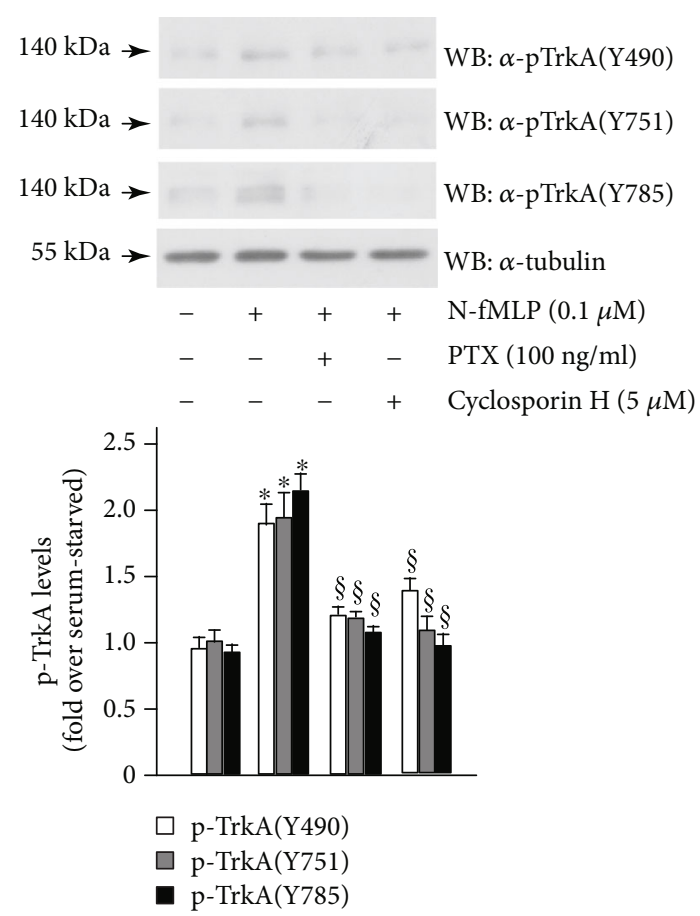

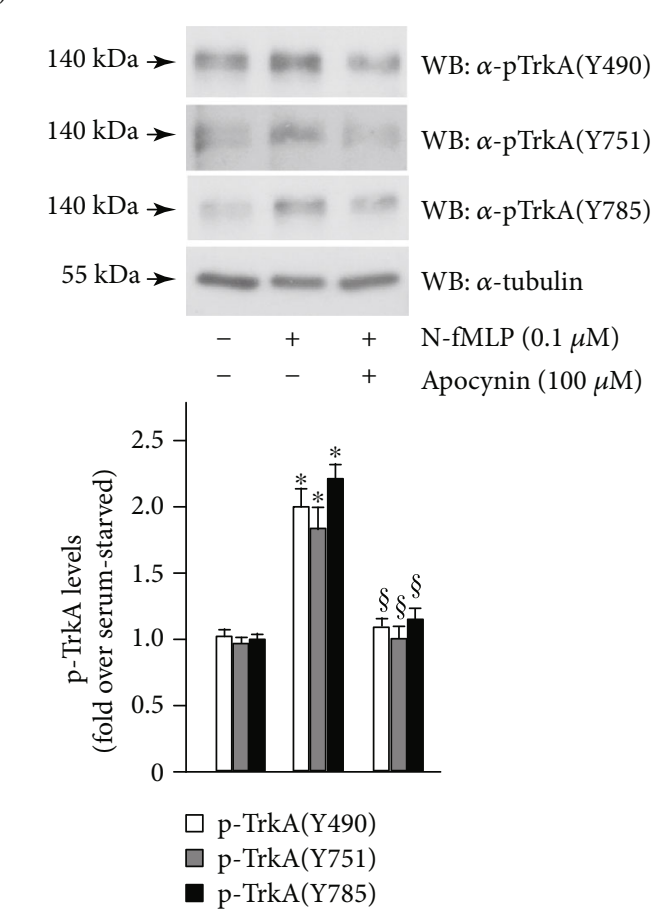

(b)

(c)

FIGURE 2: FPR1 stimulation triggers TrkA transactivation. SH-SY5Y cells were growth-arrested for 24 hours and (a) stimulated with N-fMLP for increasing time or (b) preincubated with PTX or cyclosporin $\mathrm{H}$ or (c) pretreated with apocynin, before the stimulation with $0.1 \mu \mathrm{M}$ NfMLP for 5 minutes. Fifty micrograms of total protein lysates was resolved on 10\% SDS-PAGE and immunoblotted with anti-phospho TrkA (Y490) ( $\alpha$-pTrkA(Y490)), or anti-phospho TrkA (Y751) ( $\alpha$-pTrkA(Y751)), or anti-phospho TrkA (Y785) ( $\alpha$-pTrkA(Y785)) antibodies. An anti-tubulin ( $\alpha$-tubulin) antibody was used as a control for protein loading. Bar graphs show the densitometric analysis performed on phosphorylated bands. All the experiments are representative of four independent experiments. ${ }^{*} p<0.05$ compared to unstimulated cells. ${ }^{\$} p<0.05$ compared to N-fMLP-stimulated cells. 
and p38MAP kinase (p38MAPK) pathways. Raf phosphorylates Mek1/2 which, in turn, phosphorylates ERK1/2 on serine and threonine residues.

We analyzed ERK activation in FPR1-stimulated SHSY5Y cells, and in western blot experiments, we observed that $\mathrm{N}$-fMLP induces time-dependent phosphorylation of ERK1/2 with the maximum levels of phosphorylation occurring at $5 \mathrm{~min}$ (Figure 3(a)). Preincubation of SH-SY5Y cells with PTX or cyclosporin $\mathrm{H}$, before N-fMLP stimulation, prevents ERK phosphorylation (Figure 3(b)). We also pretreated cells with apocynin (Figure 3(c)) or with GW441756 (Figure 3(d)), a potent and selective inhibitor of the ATPbinding site of the TrkA receptor, which in turn prevents its tyrosine phosphorylation and kinase activity. We observed that preincubation with apocynin or GW441756 before N-fMLP stimulation completely prevents ERK phosphorylation. On the other hand, incubation of unstimulated serum-deprived cells with PTX, or cyclosporin $\mathrm{H}$, or apocynin, or GW441756, for the above indicated times, does not modulate the expression levels of ERKs (Supplementary Figure 1). These results suggest that N-fMLP-mediated ERK1/2 activation depends on a PTX-sensitive GPCR, NOX2-dependent ROS generation, and on FPR1-dependent TrkA transactivation.

In neurons, p38MAPK activation depends on the intracellular signalling cascade triggered by Ras-mediated binding of the exchange factor RalGDS, which results in Ral activation and Src recruitment [73]. In neuronal cells, p38MAPK can be also activated via neurotrophindependent activation of $G$ proteins Rin and Rit, which belong to the Ras family [74, 75]. We observed that NfMLP stimulation of SH-SY5Y cells for $5 \mathrm{~min}$ induces a significative increase of p38MAPK phosphorylation, which is prevented by preincubation with PTX or cyclosporin $\mathrm{H}$ (Figure 3(e)).

3.4. N-fMLP-Dependent Phosphorylation of Y490 and Y751 Residues of TrkA Triggers the PI3K/Akt Pathway. PhosphoY490 of TrkA provides a recruitment site for Shc, which allows a link also for the PI3K pathway [72], and Y751 phosphorylation is essential for PI3K docking and activation [7]. PI3K generates 3-phosphate phosphoinositides, which show several effects on the development and survival of several populations of neurons. Class I of PI3Ks catalyzes in vivo the conversion of phosphatidylinositol $(4,5)$-bisphosphate into phosphatidylinositol $(3,4,5)$-trisphosphate. They also convert phosphatidylinositol into phosphatidylinositol 3-phosphate and phosphatidylinositol 4-phosphate into phosphatidylinositol (3,4)-bisphosphate in vitro. Class I of PI3Ks are activated via Ras-dependent or independent pathways [76, 77]. 3-Phosphate phosphoinositides recruit and activate phosphoinositide-dependent protein kinase 1 (PDK1) which phosphorylates and activates the serine/threonine kinase Akt.

The activity of glycogen synthase kinase 3 (GSK3) is negatively regulated by serine phosphorylation mediated by Akt [78], and, in neurons, phosphorylation-mediated GSK3 inhibition promotes the prosurvival effects induced by TrkA activation.
The PI3K/Akt/GSK3 signalling cascade may represent a diagnostic and pharmacological target for psychiatric illnesses. In human lymphocytes, PI3K levels are impaired in patients affects with schizophrenia [79] and Akt has been identified as a possible susceptibility gene for schizophrenia [80]. Furthermore, alterations of GSK3 activity represents a schizophrenia risk factor [81].

In SH-SY5Y cells, we observed time-dependent phosphorylation on Ser473 residue of Akt upon stimulation with N-fMLP (Figure 4(a)), which is prevented by preincubation with PTX, or with an FPR1 antagonist (Figure 4(b)). $\mathrm{N}$-fMLP-induced Akt(Ser 473) phosphorylation is also hampered by a NOX2 inhibitor (Figure 4(c)) or by a TrkA inhibitor (Figure 4(d)). SH-SY5Y cells were also incubated, for the above indicated times, with PTX, or cyclosporin $\mathrm{H}$, or apocynin, or GW441756 alone, and we observed that these treatments do not modulate the total expression levels of Akt (Supplementary Figure 1). Taken together, these results demonstrate that N-fMLP triggers ROS-dependent phosphorylation of Y490 and Y751 residues of TrkA which, in turn, provide docking sites for PI3K/Akt signalling.

3.5. FPR1-Mediated Phosphorylation of Y785 Residue of TrkA Provides a Docking Site for PLC $1 /$ PKC Pathway Activation. Following TrkA activation by NGF, PLC $\gamma 1$ is recruited to a phosphorylated Y785 residue. TrkA mediates phosphorylation and activation of docked PLC $\gamma 1$, which catalyzes the hydrolysis of phosphatidylinositol 4,5-bisphosphate in diacylglycerol (DAG) and inositol triphosphate (IP3). The presence of these two signalling molecules activates almost all $\mathrm{PKC}$ isoforms and many intracellular enzymes. In neuronal cells, PKC $\delta$ is required for NGF-promoted neurite outgrowth [82] and $\mathrm{PKC} \alpha$ is one of the main targets for the regulation of genes involved in neurite [83]. In the CNS, $\mathrm{PKC} \alpha, \beta$, and $\gamma$ are most extensively expressed [84] and influence neuronal signalling by short-, medium-, and long-term mechanisms [85]. In frontolimbic structures involved in mood regulation, such as hippocampus and amygdala, PKC isoenzymes are highly expressed [86] and are inhibited by lithium and valproic acid (VPA) [87]. Moreover, the regulation of processes impaired in $\mathrm{BD}$, such as neuroinflammation, oxidative stress, neuroplasticity, glutamatergic neurotransmission, neurotransmitter release, and neuronal excitability involve PKC signalling [88-93].

In SH-SY5Y cells, we observed that in response to the FPR1 agonist, PKC $\alpha$ and PKC $\delta$ translocate to the membrane and a significant increase in their level is detectable after $5 \mathrm{~min}$ of exposure (Figure 5(a)). Preincubation with PTX or cyclosporin $\mathrm{H}$ prevents membrane translocation of PKC $\alpha$ and $\mathrm{PKC} \delta$, suggesting that it depends on FPR1 activation. Furthermore, an anti-phosphoPKC $\delta(T h r 507)$ antibody detects $\mathrm{PKC} \delta$ phosphorylation and activation in cells exposed for $5 \mathrm{~min}$ to $\mathrm{N}$-fMLP but not in cells preincubated with apocynin or rottlerin, a specific $\mathrm{PKC} \delta$ inhibitor, which prevents PKC $\delta$ tyrosine phosphorylation and activation (Figure 5(b)). Incubation of SH-SY5Y cells with PTX, or cyclosporin $\mathrm{H}$, or apocynin, or rottlerin, without stimulation with the formylated peptide, does not affect the expression levels of PKC $\alpha$ and PKC $\delta$ (Supplementary Figure 1). These 

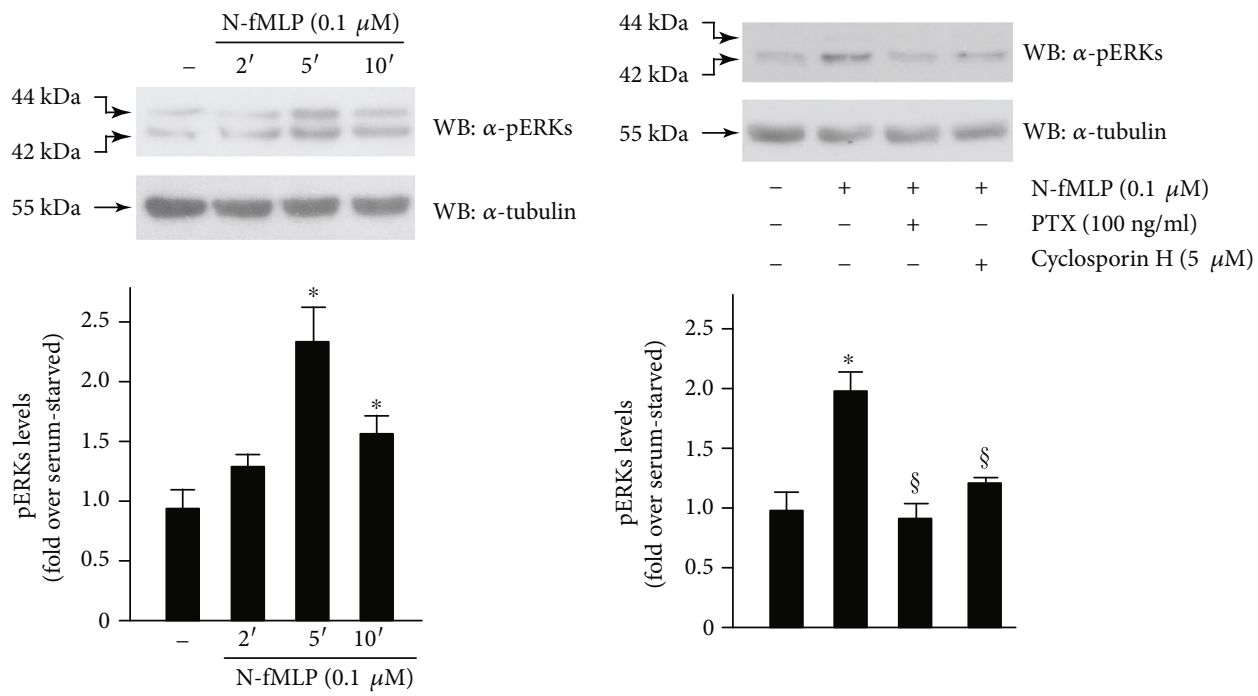

(a)

(b)
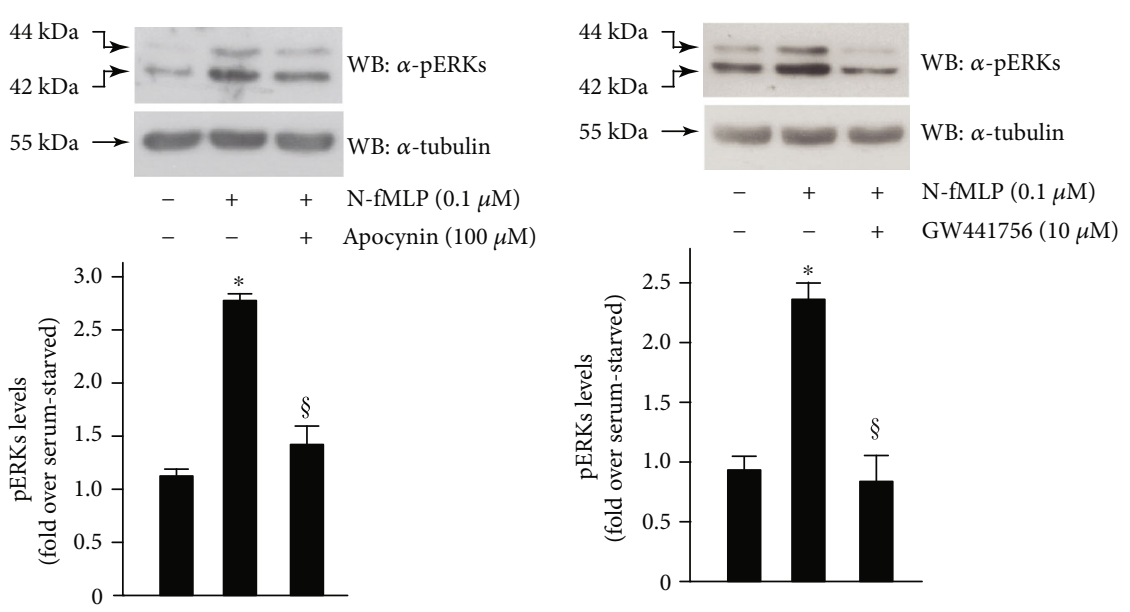

(c)

(d)
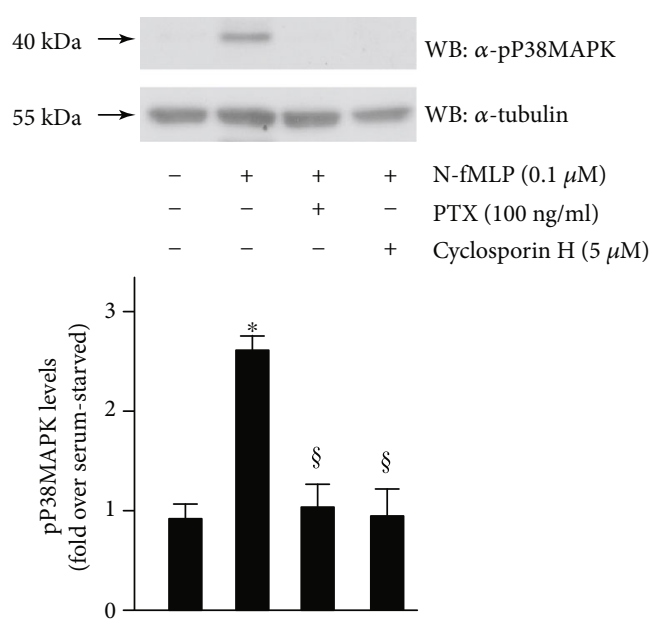

(e)

FIGURE 3: N-fMLP-induced Y490 phosphorylation is crucially involved in ERK activation. Serum-deprived SH-SY5Y cells were (a) stimulated for 2, 5, or 10 minutes with $0.1 \mu \mathrm{MN}$-fMLP or (b and e) pretreated with PTX or cyclosporin H, or (c) with apocynin, or (d) with GW441756, before the stimulation with N-fMLP for 5 minutes. Forty micrograms of whole lysates was incubated with (a, b, c, and d) an anti-phosphoERK ( $\alpha$-pERK) antibody or (e) with an anti-phospho-P38MAPK ( $\alpha$-pP38MAPK) antibody. An anti-tubulin $(\alpha$-tubulin) antibody was used as a control for protein loading. The data are representative of five independent experiments. Densitometric analysis was performed as described in Materials and Methods. ${ }^{*} p<0.05$ compared to unstimulated cells. ${ }^{\$} p<0.05$ compared to N-fMLP-stimulated cells. 


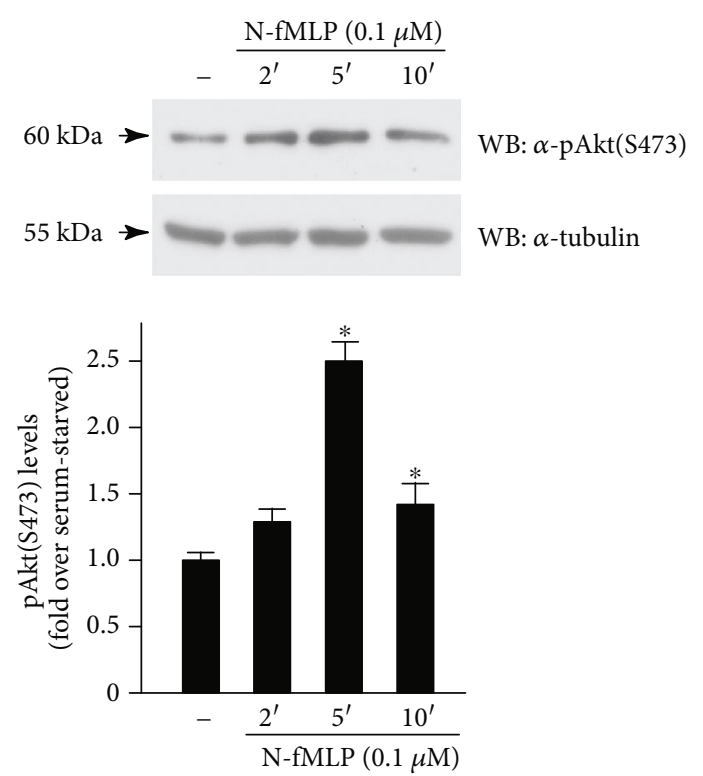

(a)
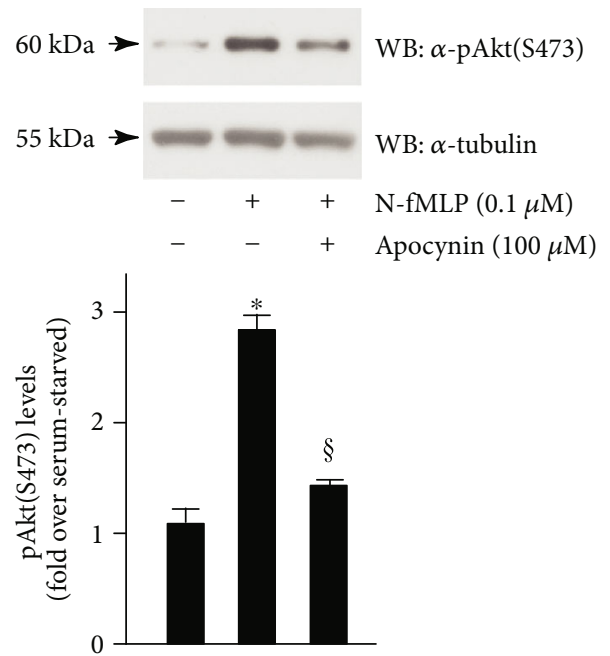

(c)
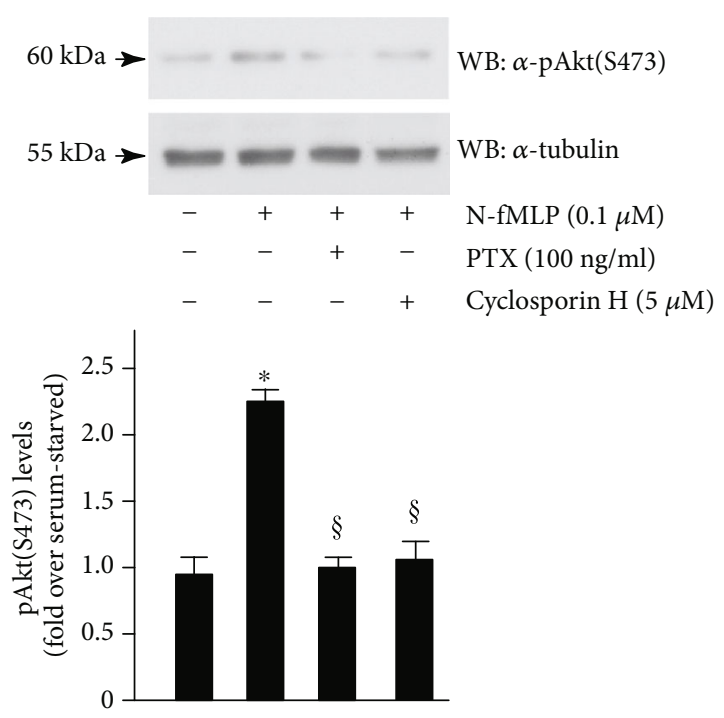

(b)

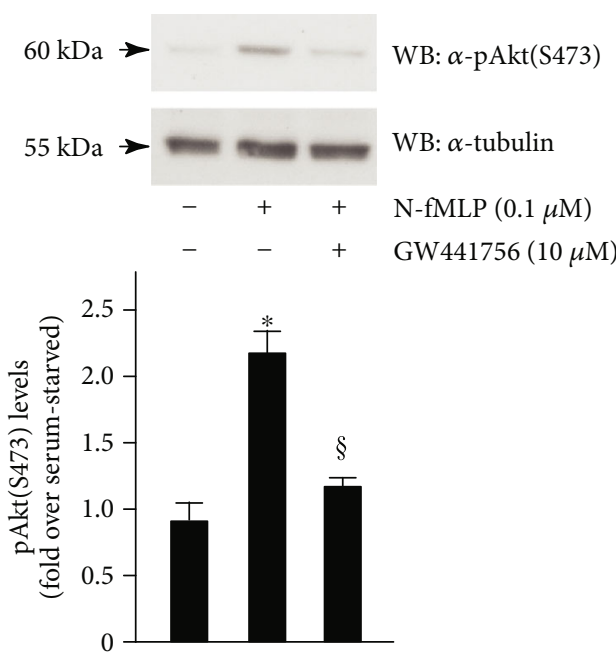

(d)

FIGURE 4: FPR1-mediated phosphorylation of Y751 residue of TrkA provides a docking site for PI3K/Akt pathway activation. SH-SY5Y cells were growth-arrested for 24 hours and (a) stimulated for 2, 5, or 10 minutes with $0.1 \mu \mathrm{M}$ N-fMLP or (b) pretreated with PTX or cyclosporin H or (c) preincubated with apocynin or (d) with GW441756, before N-fMLP stimulation. Fifty micrograms of whole lysates was immunoblotted with an anti-phospho Akt(S473) ( $\alpha$-pAkt(S473)) antibody. An anti-tubulin ( $\alpha$-tubulin) antibody was used as a control for protein loading. All the experiments are representative of five independent experiments. ${ }^{*} p<0.05$ compared to unstimulated cells. ${ }^{\$} p<0.05$ compared to NfMLP-stimulated cells.

results indicate that PKC activation requires FPR1-mediated phosphorylation of Y785 residue of TrkA and NOX2dependent ROS generation.

3.6. FPR1-Mediated TrkA Transactivation Promotes Cell Proliferation, Wound Healing, and Neurite Outgrowth. NGF stimulates growth, survival, differentiation, and maintenance of peripheral sensory and sympathetic neurons, both after injury and during development. TrkA plays a key role in neuron proliferation, differentiation, and survival in both peripheral and CNS [94, 95]. Neurotrophic factors hamper cell death, support neuronal prolif- eration and maturation, and improve the growth of affected neurons, as well as survival and regeneration of neurons $[96,97]$. There is also increasing evidence indicating the involvement of neurotrophic factors in the survival, anti-inflammation, proliferation, and differentiation of nonneuronal tissues [98]. Overall, the systemic stimulation with NGF is related with enhanced biological activity of TrkA-expressing cells and is not connected with the induction of tumor cell proliferation [99-101].

We observed that N-fMLP stimulation for 24, 48, and 72 hours induces a time-dependent proliferation of SH-SY5Y serum-deprived cells (Figure 6(a)). It is prevented by 

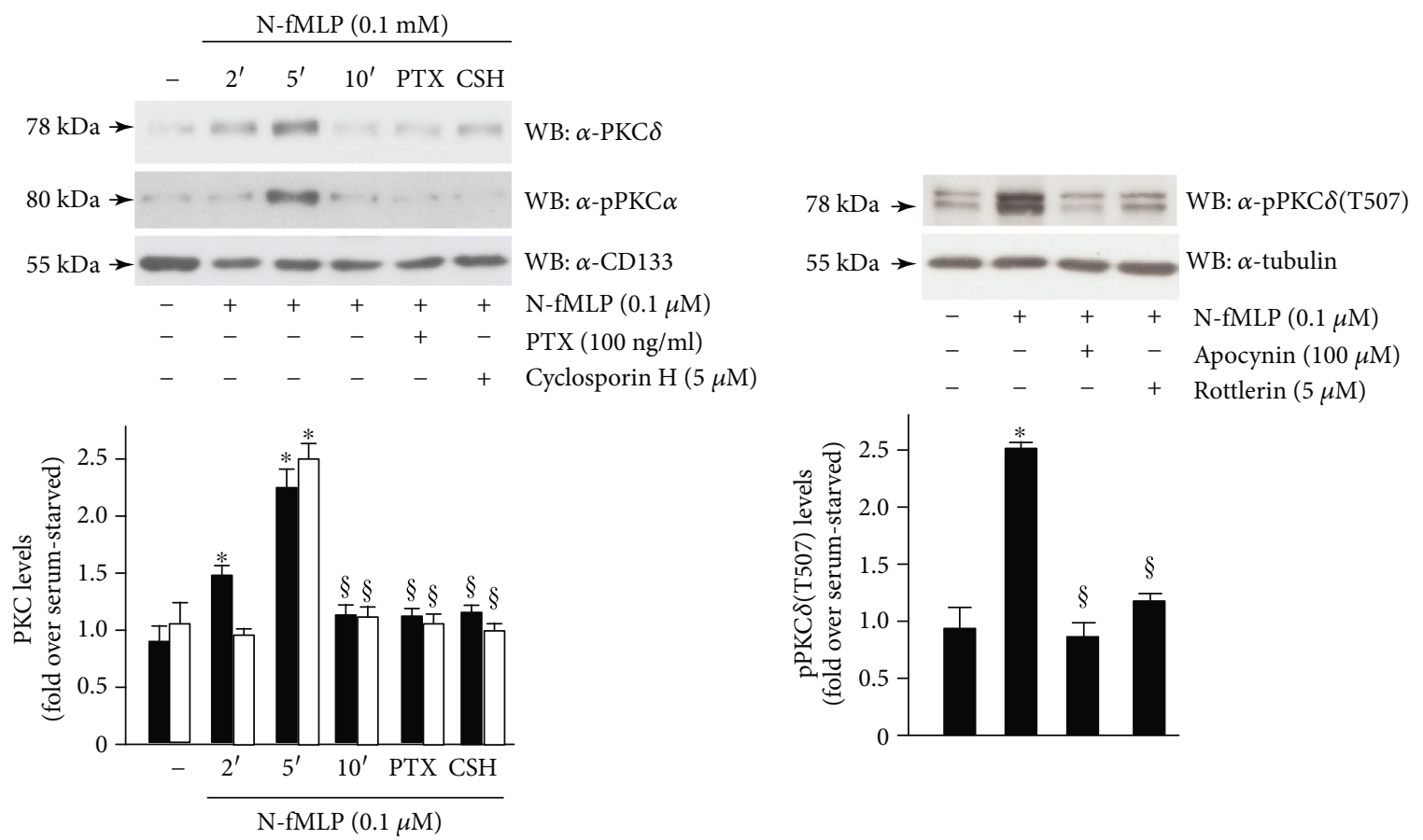

$$
\begin{aligned}
& \alpha \text {-PKC } \delta \\
& \square \text {-PKC } \alpha
\end{aligned}
$$

(b)

FiguRe 5: FPR1-mediated TrkA transactivation triggers PLC $\gamma 1 /$ PKC pathway activation. SH-SY5Y cells were serum-deprived for 24 hours and (a) stimulated for 2, 5, or 10 minutes with N-fMLP or pretreated with PTX or cyclosporin $\mathrm{H}$ before the stimulation for 5 minutes with N-fMLP. (b) Cells were also preincubated with apocynin or rottlerin before N-fMLP stimulation. Fifty micrograms of membrane lysates was immunoblotted with (a) an anti-PKC $\delta(\alpha-\mathrm{PKC} \delta)$ or anti-PKC $\alpha(\alpha-\mathrm{PKC} \alpha)$ antibody or (b) with an anti-phosphoPKC $\delta$ (T507) $(\alpha$-pPKC $\delta($ T507) $)$ antibody. An anti-CD133 ( $\alpha$-CD133) or an anti-tubulin ( $\alpha$-tubulin) antibody was used as a control for protein loading. ${ }^{*} p<0.05$ compared to unstimulated cells. ${ }^{\$} p<0.05$ compared to N-fMLP-stimulated cells.

preincubation with PTX, or cyclosporin H, or GW441756 suggesting that it depends on FPR1 activation and FPR1mediated TrkA transactivation (Figure 6(a)).

NGF plays a role also in the repair process, and the pharmacological effect of NGF in accelerating wound healing was demonstrated in both normal and healing-impaired mice [102]. NGF and TrkA are differentially expressed during tissue repair, and NGF represents a bridging factor between all the cells implicated in the healing process. During tissue reorganization and wound healing, NGF might affect epithelization or contraction by priming structural or immune resident/infiltrating cells, or via the stimulation of other profibrogenic factors.

PI3K/Akt and Ras/MAPK pathways play a key role in NGF-promoted wound healing $[103,104]$. These two signalling cascades are triggered by NGF-dependent phosphorylation of Y490 and Y751 residues of TrkA, which are also transphosphorylated upon FPR1 activation by N-fMLP (Figure 2(a)). FPR1 has chemotactic properties, and its function is to detect the appearance of harmful molecules, driving cells till the site of their release. Therefore, to evaluate whether FPR1 stimulation promotes wound closure, we analyzed SH-SY5Y cells in an in vitro wound healing assay. We observed that N-fMLP induces a more prompt cell migration after both 24 and 36 hours, compared to untreated cells (Figure 6(b)). Preincubation with PTX, or an FPR1 antago- nist, or a TrkA inhibitor prevents N-fMLP-dependent wound closure (Figure 6(b)), suggesting that it depends on FPR1 activation and TrkA transactivation.

In primary cultured dorsal root ganglion cells from normal mice, resolvin D1, which efficiently binds FPR2, stimulates neurite outgrowth [105]. FPR2 also promotes neuronal differentiation, with a longer and higher number of primary neurites per cell [106], and inhibition of FPR2 signalling reduces the length of axons and dendrites, suggesting that FPR2 is involved in axonal and dendritic outgrowth [107]. NGF induces TrkA phosphorylation on a Y785 residue, which is also transphosphorylated by FPR1 activation (Figure 2(a)) and which represents a docking site for the activation of the PLC $\gamma 1 / \mathrm{PKC}$ pathway. PKC $\delta$ and $\operatorname{PKC} \alpha$ are required for NGF-promoted neurite outgrowth and for the regulation of genes involved in neurite $[82,83]$. Therefore, we analyzed the ability of FPR1 to promote neurite outgrowth, and we observed neurite formation after 24 and 48 hours of treatment with N-fMLP (Figure 6(c)).

\section{Conclusions}

Herein, we demonstrate that in neuroblastoma SH-SY5Y cell line, FPR1 stimulation by its agonist results in NOX2dependent ROS generation and, in turn, in TrkA transactivation. The observation that apocynin prevents TrkA 


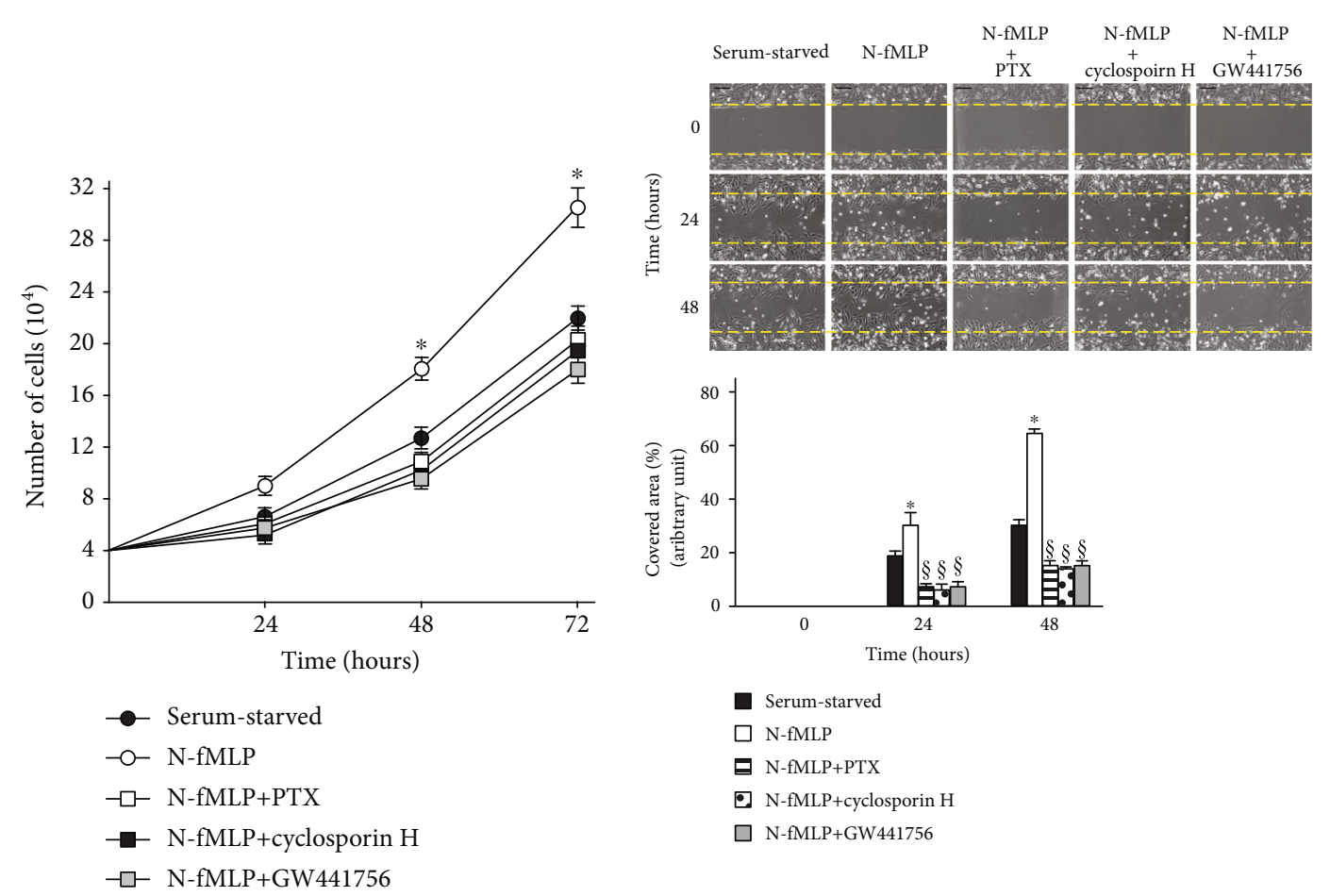

(a)

(b)
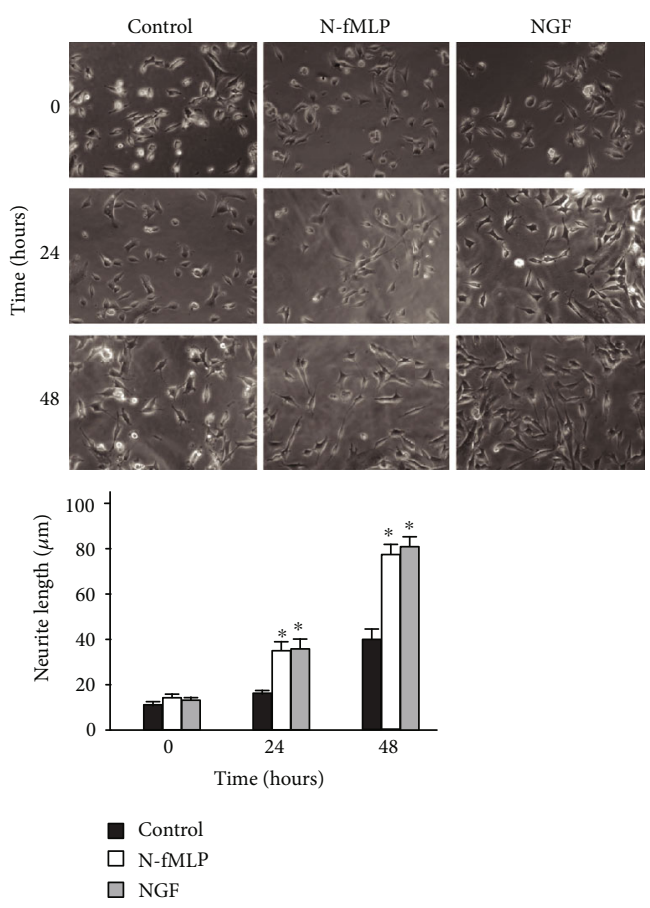

(c)

FiguRE 6: FPR1-mediated TrkA transactivation promotes SH-SY5Y cell proliferation, migration, and neurite outgrowth. (a) SH-SY5Y cells were grown in the presence or absence of $0.1 \mu \mathrm{M} \mathrm{N}$-fMLP and preincubated or not with PTX, or cyclosporin H, or GW441756. The cellular proliferation graph is representative of five independent experiments. Cell count was determined at 24, 48, and $72 \mathrm{~h}$ after plating (for all groups, $10^{4}$ cells/well). (b) Representative images (top) and bar graph quantization (bottom) of SH-SY5Y cell migration from 4 independent experiments. Cells were incubated with $0.1 \mu \mathrm{M} \mathrm{N}$-fMLP or vehicle in the presence or absence of PTX, or cyclosporin H, or GW441756. Images were acquired at 0,24 , and 48 hours after wound injury (scale bar: $20 \mu \mathrm{m}) .{ }^{*} p<0.05$ compared to unstimulated cells. ${ }^{s} p<0.05$ compared to N-fMLP-stimulated cells. (c) Representative images (top) and bar graph quantization (bottom) of SH-SY5Y neurite outgrowth from five independent experiments. Neurite length was measured in untreated SH-SY5Y cells (control) or treated with $0.1 \mu \mathrm{M}$ N-fMLP (N-fMLP) or $100 \mathrm{ng} / \mathrm{mL}$ NFG (NGF) up to 48 hours. Neurite length was measured at different times (0, 24, and 48 hours). Arrows show neurite formation. ${ }^{*} p<0.05$ compared to unstimulated cells. ${ }^{\circledR} p<0.05$ compared to N-fMLP-stimulated cells. 
transphosphorylation and the downstream signalling cascades triggered by this receptor highlights the role of ROS in cross-talking between FPR1 and TrkA. We also demonstrate that, as a result of FPR1-mediated TrkA transactivation, phosphotyrosine Y490, Y751, and Y785 of TrkA provide docking sites for the activation of Ras/MAPK, PI3K/Akt, and PLC $\gamma 1 / \mathrm{PKC}$ signalling cascades. These promote some of the downstream responses triggered by NGF stimulation, such as cell proliferation, migration, and neurite outgrowth.

The phospho-antibodies that we used to assess TrkA phosphorylation are not specific for TrkA. In fact, the anti-phospho TrkA(Y785) can recognize also Y816 of TrkB, whereas anti-phospho TrkA(Y490) detects TrkA, $\operatorname{TrkB}$, and TrkC phosphorylated isoforms. On the other hand, the anti-phospho $\operatorname{TrkA}(\mathrm{Y} 751)$ recognizes only TrkA. However, in many experiments, we blocked TrkA tyrosine kinase activity by using GW441756, which selectively inhibits TrkA and, in turn, TrkA signalling, (Figures 3, 4, 6(a), and 6(b)). Therefore, our results strongly suggest that TrkA is the isoform transactivated by FPR1. Nevertheless, we cannot exclude that also TrkB and TrkC, as well as other tyrosine kinase receptors, can be transactivated by FPR1 in $\mathrm{SH}-$ SY5Y cells. Further studies are necessary to investigate the potential contribution of other tyrosine kinase receptors in FPR1-mediated transactivation.

MAPKs play key physiological roles in the mature CNS and represent important targets for the actions of CNS-active drugs [108-110]. MAPK/ERK signalling is responsive to several drugs in the mesocorticolimbic system and is altered upon acute and chronic exposure to drugs [111]. MAPK/ERK pathway plays also an important role in fear memory reconsolidation processes, both in terms of molecular events and brain structures implicated [112]. MAPK/ERK pathway mediates many of the effects of neurotrophic factors and promotes neurite outgrowth. Accordingly, our results strongly suggest that FPR1-dependent MAPK/ERK activation promotes neurite outgrowth in SH-SY5Y cells. Mood stabilizers, such as lithium, VPA, and carbamazepine, represent a class of drugs effective in BD treatment. VPA activates the MAPK/ERK cascade [108] and induces morphological changes of human neuroblastoma cells, such as the presence of prominent growth cones and long neurites. Our results show that N-fMLP triggers the activation of FPR1/TrkA(Y490)/MAPK/ERKs cascade, suggesting that FPR1-mediated ERK activation might represent a promising therapeutical approach for $\mathrm{BD}$ treatment.

The regulation of PI3K/Akt/GSK3 signalling is involved in the etiology of depression and mood disorders [113, 114]. In animal models, Akt deletion elicits behaviour modifications that reflect the psychiatric appearance evocative of anxiety, schizophrenia, and depression [115]. The therapeutic effects of several psychiatric drugs are mediated by inhibition of the PI3K/Akt/GSK3 signalling. For instance, lithium, a mood stabilizer widely used for the treatment of depression, schizophrenia, and other mental illnesses, inhibits the GSK3 signalling [116]. In human lymphocytes, PI3K(p110) levels are altered in patients affected by schizophrenia [79]. On the other hand, Akt1 and Akt3 have been identified as possible susceptibility genes for schizophrenia [80] and Akt2 has been associated with anxiety- and depression-like behaviors [117]. Furthermore, Akt activity is decreased in some brain regions of major depression patients [118], and phosphorylated Akt levels are decreased in a depression animal model [119]. GPCRs and RTKs are involved in the activation of the PI3K/Akt/GSK3 pathway, and the selective activation of these receptors or GPCR-mediated RTK transactivation may be effective in treating some neuropsychiatric disorders. In SH-SY5Y cells, we observe that FPR1 activation by $\mathrm{N}$ fMLP triggers TrkA(Y751) transactivation, which provides a docking site for the activation of the PI3K/Akt pathway. Phosphorylated Akt might be involved in supporting the survival of immature neurons and in contributing to cell proliferation and the initial phase of neurite outgrowth [120]. Modulation of TrkA transactivation may provide a new therapeutic strategy for the treatment of depression, schizophrenia, and other mental illnesses. Lithium, which inhibits PI3K/Akt/GSK3 signalling [116], is a mood stabilizer widely used for the treatment of these disorders. However, the molecular mechanisms of the regulation of signalling activity by lithium are poorly understood, and the identification of key signalling cascades is critical to identify novel therapeutic targets. A better comprehension of the complex PI3K/Akt/GSK3 pathway and of its activation may allow an improvement both for the diagnosis and treatments.

$\mathrm{PKC}$ isoenzymes are highly expressed in the brain where they play a key role in regulating pre- and postsynaptic neurotransmission. The observation that in cortical homogenates of postmortem patients affected by $\mathrm{BD}, \mathrm{PKC}$ activity is increased in comparison with healthy controls [121] and that commonly used mood stabilizers inhibit PKC activity, highlight the importance of active PKC signalling in BD $[122,123]$. Acute lithium treatment transiently activates PKC, whereas chronic lithium exposure results in a downregulation of PKC isoenzymes in several hippocampal structures but not in cortical and subcortical districts [110]. Neurotrophic factors regulate gene expression and synaptic plasticity via PKC signalling [124]. NGF modulates PKC activity [125], PKC influences NGF expression [126], and the interdependence of these signalling cascades modulates the fine-tuning of the synaptic strength [84]. Moreover, the activation of PKC by TrkA is required for the induction of neurite outgrowth in PC12 cells [127]. In SH-SY5Y cells, we observe that FPR1 stimulation provides a docking site in Y785 of TrkA for the binding of PLC $\gamma$ and, in turn, for PKC activation. Membrane translocation of PKC $\alpha$ and PKC $\delta$, observed in N-fMLP-stimulated SH-SY5Y cells, strongly suggests that FPR1-mediated TrkA transactivation can further support neurite outgrowth.

Oxidative stress is also implicated in BD pathophysiology [128], and scavengers of ROS show pleiotropic nonspecific PKC inhibition [129]. Quercetin administration can prevent lipid peroxidation in the prefrontal cortex, hippocampus, and striatum in a mouse model of mania induced by paradoxical sleep deprivation, as well as inhibits hyperlocomotion and oxidative stress in these districts [130]. This study provides a new aspect of the role of ROS in neuronal cells. We demonstrate that FPR1-induced ROS generation plays a key role in TrkA transactivation and, in turn, in signalling 
cascades triggered by this receptor, as well as in modulating cell proliferation, migration, and neurite outgrowth.

FPR1-mediated transactivation of TrkA provides further opportunities for drug discovery approaches for neuropsychiatric disorders driven by an increase of TrkA activity. The comprehension of signalling pathways responsible for TrkA transphosphorylation and of the intracellular cascades triggered by TrkA transactivation can contribute to identify new drugs efficient to interfere with targets within the FPR1 pathway. Our results also suggest that drugs able to target simultaneously FPR1 and TrkA might have enhanced therapeutic effects in neuropsychiatric disorders, compared with targeting the receptors separately.

\section{Data Availability}

The data used to support the findings of this study are included within the article.

\section{Conflicts of Interest}

The authors declare that there is no conflict of interest regarding the publication of this paper.

\section{Acknowledgments}

This work was supported by the Regione Campania "SATIN" grant 2018-2020 and by the Federico II University of Naples, Project "Basi Molecolari del Morbo di Alzheimer," 2019.

\section{Supplementary Materials}

Supplementary Figure 1: representative western blot (top) and densitometric bar graph (bottom) analysis obtained from four independent experiments performed on whole lysates. SH-SY5Y cells were serum starved for 24 hours and incubated or not with PTX, cyclosporin $\mathrm{H}$, apocynin, or GW441756. Lysates were immunoblotted with anti-TrkA $(\alpha$-TrkA), or anti-Akt $(\alpha$-Akt), or anti-PKC $\alpha(\alpha$-PKC $\alpha)$, or anti-PKC $\delta(\alpha$-PKC $\delta)$, or anti-ERKs ( $\alpha$-ERKs) antibodies. An anti-tubulin ( $\alpha$-tubulin) antibody was used as a control for protein loading. (Supplementary Materials)

\section{References}

[1] R. A. Segal and M. E. Greenberg, "Intracellular signaling pathways activated by neurotrophic factors," Annual Review of Neuroscience, vol. 19, pp. 463-489, 1996.

[2] M. V. Chao and B. L. Hempstead, "p75 and Trk: a tworeceptor system," Trends in Neurosciences, vol. 18, no. 7, pp. 321-326, 1995.

[3] R. T. Dobrowsky, G. M. Jenkins, and Y. A. Hannun, "Neurotrophins induce sphingomyelin hydrolysis. Modulation by co-expression of p75NTR with Trk receptors," The Journal of Biological Chemistry, vol. 270, no. 38, pp. 22135-22142, 1995.

[4] S. O. Yoon, P. Casaccia-Bonnefil, B. Carter, and M. V. Chao, "Competitive signaling between TrkA and p75 nerve growth factor receptors determines cell survival," The Journal of Neuroscience, vol. 18, no. 9, pp. 3273-3281, 1998.
[5] E. J. Huang and L. F. Reichardt, "Trk receptors: roles in neuronal signal transduction," Annual Review of Biochemistry, vol. 72, pp. 609-642, 2003.

[6] J. Meldolesi, "Neurotrophin receptors in the pathogenesis, diagnosis and therapy of neurodegenerative diseases," Pharmacological Research, vol. 121, pp. 129-137, 2017.

[7] S. W. Jang, M. Okada, I. Sayeed et al., "Gambogic amide, a selective agonist for TrkA receptor that possesses robust neurotrophic activity, prevents neuronal cell death," Proceedings of the National Academy of Sciences of the United States of America, vol. 104, no. 41, pp. 16329-16334, 2007.

[8] F. Cattaneo, G. Guerra, and R. Ammendola, "Expression and signaling of formyl-peptide receptors in the brain," Neurochemical Research, vol. 35, no. 12, pp. 2018-2026, 2010.

[9] F. Cattaneo, M. Parisi, and R. Ammendola, "Distinct signaling cascades elicited by different formyl peptide receptor 2 (FPR2) agonists," International Journal of Molecular Sciences, vol. 14, no. 4, pp. 7193-7230, 2013.

[10] N. Chiang, C. N. Serhan, S. E. Dahlén et al., "The lipoxin receptor ALX: potent ligand-specific and stereoselective actions in vivo," Pharmacological Reviews, vol. 58, no. 3, pp. 463-487, 2006.

[11] G. Ying, P. Iribarren, Y. Zhou et al., "Humanin, a newly identified neuroprotective factor, uses the $G$ protein-coupled formylpeptide receptor-like-1 as a functional receptor," Journal of Immunology, vol. 172, no. 11, pp. 7078-7085, 2004.

[12] R. He, H. Sang, and R. D. Ye, "Serum amyloid A induces IL-8 secretion through a G protein-coupled receptor, FPRL1/LXA4R," Blood, vol. 101, no. 4, pp. 1572-1581, 2003.

[13] Y. Le, W. Gong, H. L. Tiffany et al., "Amyloid $\beta_{42}$ Activates a G-protein-coupled chemoattractant receptor, FPR-like-1," The Journal of Neuroscience, vol. 21, no. 2, p. RC123, 2001.

[14] M. Resnati, I. Pallavicini, J. M. Wang et al., "The fibrinolytic receptor for urokinase activates the $\mathrm{G}$ protein-coupled chemotactic receptor FPRL1/LXA4R," Proceedings of the National Academy of Sciences of the United States of America, vol. 99, no. 3, pp. 1359-1364, 2002.

[15] M. J. Rabiet, E. Huet, and F. Boulay, "Human mitochondriaderived $\mathrm{N}$-formylated peptides are novel agonists equally active on FPR and FPRL1, while Listeria monocytogenesderived peptides preferentially activate FPR," European Journal of Immunology, vol. 35, no. 8, pp. 2486-2495, 2005.

[16] A. Iaccio, F. Cattaneo, M. Mauro, and R. Ammendola, "FPRL1-mediated induction of superoxide in LL-37stimulated IMR90 human fibroblast," Archives of Biochemistry and Biophysics, vol. 481, no. 1, pp. 94-100, 2009.

[17] Y. Le, W. Gong, B. Li et al., "Utilization of two seventransmembrane, G protein-coupled receptors, formyl peptide receptor-like 1 and formyl peptide receptor, by the synthetic hexapeptide WKYMVm for human phagocyte activation," Journal of Immunology, vol. 163, no. 12, pp. 6777-6784, 1999.

[18] R. D. Ye, F. Boulay, J. M. Wang et al., "International Union of Basic and Clinical Pharmacology. LXXIII. Nomenclature for the formyl peptide receptor (FPR) family," Pharmacological Reviews, vol. 61, no. 2, pp. 119-161, 2009.

[19] B. Bufe, T. Schumann, R. Kappl et al., "Recognition of bacterial signal peptides by mammalian formyl peptide receptors: a new mechanism for sensing pathogens," The Journal of Biological Chemistry, vol. 290, no. 12, pp. 7369-7387, 2015. 
[20] R. Ammendola, L. Russo, C. de Felice, F. Esposito, T. Russo, and F. Cimino, "Low-affinity receptor-mediated induction of superoxide by $\mathrm{N}$-formyl-methionyl-leucyl-phenylalanine and WKYMVm in IMR90 human fibroblasts," Free Radical Biology \& Medicine, vol. 36, no. 2, pp. 189-200, 2004.

[21] Y. Le, P. M. Murphy, and J. M. Wang, "Formyl-peptide receptors revisited," Trends in Immunology, vol. 23, no. 11, pp. 541-548, 2002.

[22] S. Rezzola, M. Corsini, P. Chiodelli et al., "Inflammation and $\mathrm{N}$-formyl peptide receptors mediate the angiogenic activity of human vitreous humour in proliferative diabetic retinopathy," Diabetologia, vol. 60, no. 4, pp. 719-728, 2017.

[23] F. Cattaneo, M. Parisi, T. Fioretti, D. Sarnataro, G. Esposito, and R. Ammendola, "Nuclear localization of formyl-peptide receptor 2 in human cancer cells," Archives of Biochemistry and Biophysics, vol. 603, pp. 10-19, 2016.

[24] M. J. Rabiet, L. Macari, C. Dahlgren, and F. Boulay, "N-formyl peptide receptor 3 (FPR3) departs from the homologous FPR2/ALX receptor with regard to the major processes governing chemoattractant receptor regulation, expression at the cell surface, and phosphorylation," The Journal of Biological Chemistry, vol. 286, no. 30, pp. 26718-26731, 2011.

[25] D. A. Dorward, C. D. Lucas, G. B. Chapman, C. Haslett, K. Dhaliwal, and A. G. Rossi, "The role of formylated peptides and formyl peptide receptor 1 in governing neutrophil function during acute inflammation," The American Journal of Pathology, vol. 185, no. 5, pp. 1172-1184, 2015.

[26] J. Dalli, A. P. Consalvo, V. Ray et al., "Proresolving and tissue-protective actions of annexin A1-based cleavageresistant peptides are mediated by formyl peptide receptor 2/lipoxin $\mathrm{A}_{4}$ receptor," Journal of Immunology, vol. 190, no. 12, pp. 6478-6487, 2013.

[27] E. L. Becker, F. A. Forouhar, M. L. Grunnet et al., "Broad immunocytochemical localization of the formylpeptide receptor in human organs, tissues, and cells," Cell and Tissue Research, vol. 292, no. 1, pp. 129-135, 1998.

[28] S. D. Liberles, L. F. Horowitz, D. Kuang et al., "Formyl peptide receptors are candidate chemosensory receptors in the vomeronasal organ," Proceedings of the National Academy of Sciences of the United States of America, vol. 106, no. 24, pp. 9842-9847, 2009.

[29] S. Rivière, L. Challet, D. Fluegge, M. Spehr, and I. Rodriguez, "Formyl peptide receptor-like proteins are a novel family of vomeronasal chemosensors," Nature, vol. 459, no. 7246, pp. 574-577, 2009.

[30] J. L. Gao, E. H. Schneider, E. L. Dimitrov et al., "Reduced fear memory and anxiety-like behavior in mice lacking formylpeptide receptor 1," Behavior Genetics, vol. 41, no. 5, pp. 724-733, 2011.

[31] I. Gallo, L. Rattazzi, G. Piras et al., "Formyl peptide receptor as a novel therapeutic target for anxiety-related disorders," PLoS One, vol. 9, no. 12, article e114626, 2014.

[32] F. Cattaneo, G. Guerra, M. Parisi et al., "Cell-surface receptors transactivation mediated by $\mathrm{G}$ protein-coupled receptors," International Journal of Molecular Sciences, vol. 15, no. 11, pp. 19700-19728, 2014.

[33] K. Bedard and K. H. Krause, "The NOX family of ROSgenerating NADPH oxidases: physiology and pathophysiology," Physiological Reviews, vol. 87, no. 1, pp. 245-313, 2007.

[34] A. Iaccio, C. Collinet, N. M. Gesualdi, and R. Ammendola, "Protein kinase C- $\alpha$ and $-\delta$ are required for NADPH oxidase activation in WKYMVm-stimulated IMR90 human fibroblasts," Archives of Biochemistry and Biophysics, vol. 459, no. 2, pp. 288-294, 2007.

[35] F. Cattaneo, M. Parisi, and R. Ammendola, "WKYMVminduced cross-talk between FPR2 and HGF receptor in human prostate epithelial cell line PNT1A," FEBS Letters, vol. 587, no. 10, pp. 1536-1542, 2013.

[36] F. Cattaneo, M. Castaldo, M. Parisi, R. Faraonio, G. Esposito, and R. Ammendola, "Formyl peptide receptor 1 modulates endothelial cell functions by NADPH oxidase-dependent VEGFR2 transactivation," Oxidative Medicine and Cellular Longevity, vol. 2018, Article ID 2609847, 12 pages, 2018.

[37] F. Cattaneo, A. Iaccio, G. Guerra, S. Montagnani, and R. Ammendola, "NADPH-oxidase-dependent reactive oxygen species mediate EGFR transactivation by FPRL1 in WKYMVm-stimulated human lung cancer cells," Free Radical Biology \& Medicine, vol. 51, no. 6, pp. 11261136, 2011.

[38] F. S. Lee and M. V. Chao, "Activation of Trk neurotrophin receptors in the absence of neurotrophins," Proceedings of the National Academy of Sciences of the United States of America, vol. 98, no. 6, pp. 3555-3560, 2001.

[39] N. El Zein, S. D'Hondt, and E. Sariban, "Crosstalks between the receptors tyrosine kinase EGFR and TrkA and the GPCR, $\mathrm{FPR}$, in human monocytes are essential for receptorsmediated cell activation," Cellular Signalling, vol. 22, no. 10, pp. 1437-1447, 2010.

[40] F. S. Lee, R. Rajagopal, and M. V. Chao, "Distinctive features of Trk neurotrophin receptor transactivation by G proteincoupled receptors," Cytokine \& Growth Factor Reviews, vol. 13, no. 1, pp. 11-17, 2002.

[41] F. S. Lee, R. Rajagopal, A. H. Kim, P. C. Chang, and M. V. Chao, "Activation of Trk neurotrophin receptor signaling by pituitary adenylate cyclase-activating polypeptides," The Journal of Biological Chemistry, vol. 277, no. 11, pp. 90969102, 2002.

[42] C. R. A. F. Diniz, P. C. Casarotto, S. M. Fred, C. Biojone, E. Castrén, and S. R. L. Joca, "Antidepressant-like effect of losartan involves TRKB transactivation from angiotensin receptor type 2 (AGTR2) and recruitment of FYN," Neuropharmacology, vol. 135, pp. 163-171, 2018.

[43] G. G. Schiattarella, F. Cattaneo, G. Pironti et al., “Akap1 deficiency promotes mitochondrial aberrations and exacerbates cardiac injury following permanent coronary ligation via enhanced mitophagy and apoptosis," PLoS One, vol. 11, no. 5, article e0154076, 2016.

[44] R. Caggiano, F. Cattaneo, O. Moltedo et al., "miR-128 is implicated in stress responses by targeting MAFG in skeletal muscle cells," Oxidative Medicine and Cellular Longevity, vol. 2017, Article ID 9308310, 13 pages, 2017.

[45] S. De Marino, F. Cattaneo, C. Festa et al., "Imbricatolic acid from Juniperus communis L. prevents cell cycle progression in CaLu-6 cells," Planta Medica, vol. 77, no. 16, pp. $1822-$ 1828, 2011.

[46] G. G. Schiattarella, F. Cattaneo, A. Carrizzo et al., “Akap1 regulates vascular function and endothelial cells behavior," Hypertension, vol. 71, no. 3, pp. 507-517, 2018.

[47] F. Cattaneo, S. de Marino, M. Parisi et al., "Wound healing activity and phytochemical screening of purified fractions of Sempervivum tectorum L. leaves on HCT 116," Phytochemical Analysis, vol. 30, no. 5, pp. 524-534, 2019. 
[48] H. Xicoy, B. Wieringa, and G. J. M. Martens, "The SH-SY5Y cell line in Parkinson's disease research: a systematic review," Molecular Neurodegeneration, vol. 12, no. 1, p. 10, 2017.

[49] R. Nciri, E. Bourogaa, S. Jbahi et al., "Chronic neuroprotective effects of low concentration lithium on SH-SY5Y cells: possible involvement of stress proteins and gene expression," Neural Regeneration Research, vol. 9, no. 7, pp. 735-740, 2014.

[50] A. Romero, J. Egea, G. C. González-Muñoz et al., "ITH12410/SC058: a new neuroprotective compound with potential in the treatment of Alzheimer's disease," ACS Chemical Neuroscience, vol. 5, no. 9, pp. 770-775, 2014.

[51] Y. J. Li, W. Zhao, X. J. Yu et al., "Activation of p47phox as a mechanism of bupivacaine-induced burst production of reactive oxygen species and neural toxicity," Oxidative Medicine and Cellular Longevity, vol. 2017, Article ID 8539026, 14 pages, 2017.

[52] M. Nitti, A. L. Furfaro, N. Traverso et al., "PKC delta and NADPH oxidase in AGE-induced neuronal death," Neuroscience Letters, vol. 416, no. 3, pp. 261-265, 2007.

[53] S. P. Tammariello, M. T. Quinn, and S. Estus, "NADPH oxidase contributes directly to oxidative stress and apoptosis in nerve growth factor-deprived sympathetic neurons," The Journal of Neuroscience, vol. 20, no. 1, article RC53, 2000.

[54] A. Kamsler and M. Segal, "Hydrogen peroxide as a diffusible signal molecule in synaptic plasticity," Molecular Neurobiology, vol. 29, no. 2, pp. 167-178, 2004.

[55] L. T. Knapp and E. Klann, "Role of reactive oxygen species in hippocampal long-term potentiation: contributory or inhibitory?," Journal of Neuroscience Research, vol. 70, no. 1, pp. 1$7,2002$.

[56] K. T. Kishida, M. Pao, S. M. Holland, and E. Klann, "NADPH oxidase is required for NMDA receptor-dependent activation of ERK in hippocampal area CA1," Journal of Neurochemistry, vol. 94, no. 2, pp. 299-306, 2005.

[57] K. T. Kishida, C. A. Hoeffer, D. Hu, M. Pao, S. M. Holland, and E. Klann, "Synaptic plasticity deficits and mild memory impairments in mouse models of chronic granulomatous disease," Molecular and Cellular Biology, vol. 26, no. 15, pp. 5908-5920, 2006.

[58] S. H. Choi, D. Y. Lee, E. S. Chung, Y. B. Hong, S. U. Kim, and B. K. Jin, "Inhibition of thrombin-induced microglial activation and NADPH oxidase by minocycline protects dopaminergic neurons in the substantia nigra in vivo," Journal of Neurochemistry, vol. 95, no. 6, pp. 1755-1765, 2005.

[59] D. Zekry, T. K. Epperson, and K. H. Krause, “A role for NOX NADPH oxidases in Alzheimer's disease and other types of dementia?," IUBMB Life, vol. 55, no. 6, pp. 307-313, 2003.

[60] G. Khayrullina, S. Bermudez, and K. R. Byrnes, "Inhibition of NOX2 reduces locomotor impairment, inflammation, and oxidative stress after spinal cord injury," Journal of Neuroinflammation, vol. 12, no. 1, p. 172, 2015.

[61] R. Russo, F. Cattaneo, P. Lippiello et al., "Motor coordination and synaptic plasticity deficits are associated with increased cerebellar activity of NADPH oxidase, CAMKII, and PKC at preplaque stage in the TgCRND8 mouse model of Alzheimer's disease," Neurobiology of Aging, vol. 68, pp. 123-133, 2018.

[62] R. P. Brandes, N. Weissmann, and K. Schröder, "Nox family NADPH oxidases: molecular mechanisms of activation," Free Radical Biology \& Medicine, vol. 76, pp. 208-226, 2014.
[63] G. Minnone, F. De Benedetti, and L. Bracci-Laudiero, "NGF and its receptors in the regulation of inflammatory response," International Journal of Molecular Sciences, vol. 18, no. 5, p. 1028, 2017.

[64] Q. Miao, K. Ma, D. Chen, X. Wu, and S. Jiang, "Targeting tropomyosin receptor kinase for cancer therapy," European Journal of Medicinal Chemistry, vol. 175, pp. 129-148, 2019.

[65] P. J. G. Cussell, M. S. Howe, T. A. Illingworth, M. Gomez Escalada, N. G. N. Milton, and A. W. J. Paterson, "The formyl peptide receptor agonist FPRa14 induces differentiation of Neuro2a mouse neuroblastoma cells into multiple distinct morphologies which can be specifically inhibited with FPR antagonists and FPR knockdown using siRNA," PLoS One, vol. 14, no. 6, article e0217815, 2019.

[66] Y. C. Chen, Y. J. Chiu, C. H. Lin et al., "Indole compound NC009-1 augments APOE and TRKA in Alzheimer's disease cell and mouse models for neuroprotection and cognitive improvement," Journal of Alzheimer's Disease, vol. 67, no. 2, pp. 737-756, 2019.

[67] P. Chiarugi and P. Cirri, "Redox regulation of protein tyrosine phosphatases during receptor tyrosine kinase signal transduction," Trends in Biochemical Sciences, vol. 28, no. 9, pp. 509-514, 2003.

[68] C. H. Yang, Y. J. Yeh, J. Y. Wang et al., "NEAP/DUSP26 suppresses receptor tyrosine kinases and regulates neuronal development in zebrafish," Scientific Reports, vol. 7, no. 1, article 5241, 2017.

[69] D. Zhang, M. C. Marlin, Z. Liang et al., "The protein tyrosine phosphatase MEG2 regulates the transport and signal transduction of tropomyosin receptor kinase a," The Journal of Biological Chemistry, vol. 291, no. 46, pp. 23895-23905, 2016.

[70] X. Montano, "Repression of SHP-1 expression by p53 leads to trkA tyrosine phosphorylation and suppression of breast cancer cell proliferation," Oncogene, vol. 28, no. 43, pp. 37873800, 2009.

[71] L. F. Reichardt, "Neurotrophin-regulated signalling pathways," Philosophical Transactions of the Royal Society of London. Series B, Biological Sciences, vol. 361, no. 1473, pp. 15451564, 2006.

[72] K. N. Robinson, K. Manto, R. J. Buchsbaum, J. MacDonald, and S. O. Meakin, "Neurotrophin-dependent tyrosine phosphorylation of Ras guanine-releasing factor 1 and associated neurite outgrowth is dependent on the HIKE domain of TrkA," The Journal of Biological Chemistry, vol. 280, no. 1, pp. 225-235, 2005.

[73] D. M. Ouwens, N. D. de Ruiter, G. van der Zon et al., "Growth factors can activate ATF2 via a two-step mechanism: phosphorylation of Thr71 through the Ras-MEK-ERK pathway and of Thr69 through RalGDS-Src-p38," The EMBO Journal, vol. 21, no. 14, pp. 3782-3793, 2002.

[74] G. X. Shi and D. A. Andres, "Rit contributes to nerve growth factor-induced neuronal differentiation via activation of BRaf-extracellular signal-regulated kinase and p38 mitogenactivated protein kinase cascades," Molecular and Cellular Biology, vol. 25, no. 2, pp. 830-846, 2005.

[75] G. X. Shi, J. Han, and D. A. Andres, "Rin GTPase couples nerve growth factor signaling to p38 and b-Raf/ERK pathways to promote neuronal differentiation," The Journal of Biological Chemistry, vol. 280, no. 45, pp. 37599-37609, 2005.

[76] B. Vanhaesebroeck, S. J. Leevers, K. Ahmadi et al., "Synthesis and function of 3-phosphorylated inositol lipids," Annual Review of Biochemistry, vol. 70, pp. 535-602, 2001. 
[77] J. Yuan and B. A. Yankner, "Apoptosis in the nervous system," Nature, vol. 407, no. 6805, pp. 802-809, 2000.

[78] C. Sutherland and P. Cohen, "The alpha-isoform of glycogen synthase kinase- 3 from rabbit skeletal muscle is inactivated by 70 S6 kinase or MAP kinase-activated protein kinase-1 in vitro," FEBS Letters, vol. 338, no. 1, pp. 37-42, 1994.

[79] A. J. Law, Y. Wang, Y. Sei et al., "Neuregulin 1-ErbB4-PI3K signaling in schizophrenia and phosphoinositide 3-kinasep $110 \delta$ inhibition as a potential therapeutic strategy," Proceedings of the National Academy of Sciences of the United States of America, vol. 109, no. 30, pp. 12165-12170, 2012.

[80] E. S. Emamian, D. Hall, M. J. Birnbaum, M. Karayiorgou, and J. A. Gogos, "Convergent evidence for impaired AKT1GSK3 $\beta$ signaling in schizophrenia," Nature Genetics, vol. 36, no. 2, pp. 131-137, 2004.

[81] P. Yan, X. Qiao, H. Wu et al., “An association study between genetic polymorphisms in functional regions of five genes and the risk of schizophrenia," Journal of Molecular Neuroscience, vol. 59, no. 3, pp. 366-375, 2016.

[82] K. C. Corbit, D. A. Foster, and M. R. Rosner, "Protein kinase Cdelta mediates neurogenic but not mitogenic activation of mitogen-activated protein kinase in neuronal cells," Molecular and Cellular Biology, vol. 19, no. 6, pp. 4209-4218, 1999.

[83] J. Alfonso, L. R. Frick, D. M. Silberman, M. L. Palumbo, A. M. Genaro, and A. C. Frasch, "Regulation of hippocampal gene expression is conserved in two species subjected to different stressors and antidepressant treatments," Biological Psychiatry, vol. 59, no. 3, pp. 244-251, 2006.

[84] A. Saxena, G. Scaini, D. V. Bavaresco et al., "Role of protein kinase $\mathrm{C}$ in bipolar disorder: a review of the current literature," Molecular Neuropsychiatry, vol. 3, no. 2, pp. 108-124, 2017.

[85] M. Amadio, F. Battaini, and A. Pascale, "The different facets of protein kinases C: old and new players in neuronal signal transduction pathways," Pharmacological Research, vol. 54, no. 5 , pp. $317-325,2006$.

[86] M. U. Naik, E. Benedikz, I. Hernandez et al., "Distribution of protein kinase Mzeta and the complete protein kinase C isoform family in rat brain," The Journal of Comparative Neurology, vol. 426, no. 2, pp. 243-258, 2000.

[87] C. A. Zarate and H. K. Manji, "Protein kinase C inhibitors: rationale for use and potential in the treatment of bipolar disorder," CNS Drugs, vol. 23, no. 7, pp. 569-582, 2009.

[88] N. Suganthy, K. P. Devi, S. F. Nabavi, N. Braidy, and S. M. Nabavi, "Bioactive effects of quercetin in the central nervous system: focusing on the mechanisms of actions," Biomedicine \& Pharmacotherapy, vol. 84, pp. 892-908, 2016.

[89] S. H. Hadley, P. K. Bahia, and T. E. Taylor-Clark, "Sensory nerve terminal mitochondrial dysfunction induces hyperexcitability in airway nociceptors via protein kinase C," Molecular Pharmacology, vol. 85, no. 6, pp. 839-848, 2014.

[90] Y. Chu, D. Fioravante, M. Leitges, and W. G. Regehr, "Calcium-dependent PKC isoforms have specialized roles in short-term synaptic plasticity," Neuron, vol. 82, no. 4, pp. 859-871, 2014.

[91] C. A. Zarate Jr., J. Du, J. Quiroz et al., "Regulation of cellular plasticity cascades in the pathophysiology and treatment of mood disorders: role of the glutamatergic system," Annals of the New York Academy of Sciences, vol. 1003, no. 1, pp. 273-291, 2003.
[92] F. Opazo, J. B. Schulz, and B. H. Falkenburger, "PKC links Gq-coupled receptors to DAT-mediated dopamine release," Journal of Neurochemistry, vol. 114, no. 2, pp. 587-596, 2010.

[93] S. Pahl, D. Tapken, S. C. Haering, and M. Hollmann, "Trafficking of kainate receptors," Membranes, vol. 4, no. 3, pp. 565-595, 2014.

[94] R. Levi-Montalcini, "The nerve growth factor 35 years later," Science, vol. 237, no. 4819, pp. 1154-1162, 1987.

[95] L. Aloe and R. Levi-Montalcini, "Nerve growth factorinduced transformation of immature chromaffin cells in vivo into sympathetic neurons: effect of antiserum to nerve growth factor," Proceedings of the National Academy of Sciences of the United States of America, vol. 76, no. 3, pp. 1246-1250, 1979.

[96] A. M. Sullivan and G. W. O'Keeffe, "Neurotrophic factor therapy for Parkinson's disease: past, present and future," Neural Regeneration Research, vol. 11, no. 2, pp. 205-207, 2016.

[97] T. B. Sampaio, A. S. Savall, M. E. Z. Gutierrez, and S. Pinton, "Neurotrophic factors in Alzheimer's and Parkinson's diseases: implications for pathogenesis and therapy," Neural Regeneration Research, vol. 12, no. 4, pp. 549-557, 2017.

[98] M. Bothwell, "Recent advances in understanding neurotrophin signaling," F1000Research, vol. 5, article 1885, 2016.

[99] M. V. Sofroniew, C. L. Howe, and W. C. Mobley, "Nerve growth factor signaling, neuroprotection, and neural repair," Annual Review of Neuroscience, vol. 24, no. 1, pp. 1217-1281, 2001.

[100] R. Levi-Montalcini and P. U. Angeletti, "Nerve growth factor," Physiological Reviews, vol. 48, no. 3, pp. 534-569, 1968.

[101] L. Dubanet, H. Bentayeb, B. Petit et al., "Anti-apoptotic role and clinical relevance of neurotrophins in diffuse large Bcell lymphomas," British Journal of Cancer, vol. 113, no. 6, pp. 934-944, 2015.

[102] H. Matsuda, H. Koyama, H. Sato et al., "Role of nerve growth factor in cutaneous wound healing: accelerating effects in normal and healing-impaired diabetic mice," The Journal of Experimental Medicine, vol. 187, no. 3, pp. 297-306, 1998.

[103] M. Zhang, Y. Zhang, J. Ding et al., "The role of TrkA in the promoting wounding-healing effect of CD271 on epidermal stem cells," Archives of Dermatological Research, vol. 310, no. 9, pp. 737-750, 2018.

[104] J. C. Chen, B. B. Lin, H. W. Hu et al., "NGF accelerates cutaneous wound healing by promoting the migration of dermal fibroblasts via the PI3K/Akt-Rac1-JNK and ERK pathways," BioMed Research International, vol. 2014, Article ID 547187, 13 pages, 2014.

[105] H. Shevalye, M. S. Yorek, L. J. Coppey et al., "Effect of enriching the diet with menhaden oil or daily treatment with resolvin D1 on neuropathy in a mouse model of type 2 diabetes," Journal of Neurophysiology, vol. 114, no. 1, pp. 199-208, 2015.

[106] L. Zhang, G. Wang, X. Chen et al., "Formyl peptide receptors promotes neural differentiation in mouse neural stem cells by ROS generation and regulation of PI3K-AKT signaling," Scientific Reports, vol. 7, no. 1, p. 206, 2017.

[107] C. F. Ho, N. B. Ismail, J. K. Koh et al., "Localisation of formylpeptide receptor 2 in the rat central nervous system and its role in axonal and dendritic outgrowth," Neurochemical Research, vol. 43, no. 8, pp. 1587-1598, 2018. 
[108] P. X. Yuan, L. D. Huang, Y. M. Jiang, J. S. Gutkind, H. K. Manji, and G. Chen, "The mood stabilizer valproic acid activates mitogen-activated protein kinases and promotes neurite growth," The Journal of Biological Chemistry, vol. 276, no. 34, pp. 31674-31683, 2001.

[109] T. D. Gould, G. Chen, and H. K. Manji, "Mood stabilizer psychopharmacology," Clinical Neuroscience Research, vol. 2, no. 3-4, pp. 193-212, 2002.

[110] H. K. Manji and G. Chen, "PKC, MAP kinases and the bcl-2 family of proteins as long-term targets for mood stabilizers," Molecular Psychiatry, vol. 7, Supplement 1, pp. S46-S56, 2002.

[111] W. L. Sun, P. M. Quizon, and J. Zhu, "Molecular mechanism: ERK signaling, drug addiction, and behavioral effects," Progress in Molecular Biology and Translational Science, vol. 137, pp. 1-40, 2016.

[112] V. Cestari, C. Rossi-Arnaud, D. Saraulli, and M. Costanzi, "The MAP $(\mathrm{K})$ of fear: from memory consolidation to memory extinction," Brain Research Bulletin, vol. 105, pp. 8-16, 2014.

[113] J. M. Beaulieu, "A role for Akt and glycogen synthase kinase3 as integrators of dopamine and serotonin neurotransmission in mental health," Journal of Psychiatry \& Neuroscience, vol. 37, no. 1, pp. 7-16, 2012.

[114] S. Matsuda, Y. Ikeda, M. Murakami, Y. Nakagawa, A. Tsuji, and Y. Kitagishi, "Roles of PI3K/AKT/GSK3 pathway involved in psychiatric illnesses," Diseases, vol. 7, no. 1 , p. 22, 2019.

[115] E. J. Nestler and S. E. Hyman, "Animal models of neuropsychiatric disorders," Nature Neuroscience, vol. 13, no. 10, pp. 1161-1169, 2010.

[116] L. Freland and J. M. Beaulieu, "Inhibition of GSK3 by lithium, from single molecules to signaling networks," Frontiers in Molecular Neuroscience, vol. 5, p. 14, 2012.

[117] C. Leibrock, T. F. Ackermann, M. Hierlmeier, F. Lang, S. Borgwardt, and U. E. Lang, "Akt2 deficiency is associated with anxiety and depressive behavior in mice," Cellular Physiology and Biochemistry, vol. 32, no. 3, pp. 766-777, 2013.

[118] F. Karege, N. Perroud, S. Burkhardt et al., "Alteration in kinase activity but not in protein levels of protein kinase B and glycogen synthase kinase- $3 \beta$ in ventral prefrontal cortex of depressed suicide victims," Biological Psychiatry, vol. 61, no. 2, pp. 240-245, 2007.

[119] V. Krishnan, M. H. Han, M. Mazei-Robison et al., "AKT signaling within the ventral tegmental area regulates cellular and behavioral responses to stressful stimuli," Biological Psychiatry, vol. 64, no. 8, pp. 691-700, 2008.

[120] N. Nusser, E. Gosmanova, Y. Zheng, and G. Tigyi, "Nerve growth factor signals through TrkA, phosphatidylinositol 3kinase, and Racl to inactivate RhoA during the initiation of neuronal differentiation of PC12 cells," The Journal of Biological Chemistry, vol. 277, no. 39, pp. 35840-35846, 2002.

[121] H. Y. Wang and E. Friedman, "Enhanced protein kinase C activity and translocation in bipolar affective disorder brains," Biological Psychiatry, vol. 40, no. 7, pp. 568-575, 1996.

[122] H. Y. Wang and E. Friedman, "Lithium inhibition of protein kinase C activation-induced serotonin release," Psychopharmacology, vol. 99, no. 2, pp. 213-218, 1989.

[123] J. A. Bitran, W. Z. Potter, H. K. Manji, and F. Gusovsky, "Chronic $\mathrm{Li}^{+}$attenuates agonist- and phorbol ester- mediated $\mathrm{Na}^{+} / \mathrm{H}^{+}$antiporter activity in HL-60 cells," European Journal of Pharmacology, vol. 188, no. 4-5, pp. 193-202, 1990.

[124] J. C. Arévalo and S. H. Wu, "Neurotrophin signaling: many exciting surprises!," Cellular and Molecular Life Sciences, vol. 63, no. 13, pp. 1523-1537, 2006.

[125] Y. H. Zhang, J. Kays, K. E. Hodgdon, T. C. Sacktor, and G. D. Nicol, "Nerve growth factor enhances the excitability of rat sensory neurons through activation of the atypical protein kinase C isoform, РКM $\zeta$," Journal of Neurophysiology, vol. 107, no. 1, pp. 315-335, 2012.

[126] J. G. Lee, H. Y. Cho, S. W. Park, M. K. Seo, and Y. H. Kim, "Effects of olanzapine on brain-derived neurotrophic factor gene promoter activity in SH-SY5Y neuroblastoma cells," Progress in Neuro-Psychopharmacology \& Biological Psychiatry, vol. 34, no. 6, pp. 1001-1006, 2010.

[127] M. Tsuji, O. Inanami, and M. Kuwabara, "Induction of neurite outgrowth in PC12 cells by alpha-phenyl-N-tertbutylnitron through activation of protein kinase $\mathrm{C}$ and the Ras-extracellular signal-regulated kinase pathway," The Journal of Biological Chemistry, vol. 276, no. 35, pp. 32779-32785, 2001.

[128] G. Morris, K. Walder, S. L. McGee et al., "A model of the mitochondrial basis of bipolar disorder," Neuroscience \& Biobehavioral Reviews, vol. 74, Part A, pp. 1-20, 2017.

[129] G. L. Russo, M. Russo, C. Spagnuolo et al., "Quercetin: a pleiotropic kinase inhibitor against cancer," Cancer Treatment and Research, vol. 159, pp. 185-205, 2014.

[130] L. K. Kanazawa, D. D. Vecchia, E. M. Wendler et al., "Effects of acute and chronic quercetin administration on methylphenidate-induced hyperlocomotion and oxidative stress," Life Sciences, vol. 171, pp. 1-8, 2017. 


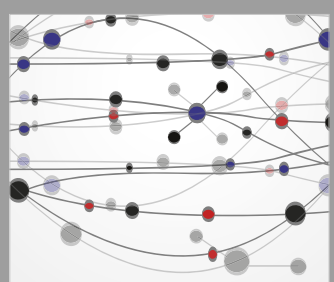

The Scientific World Journal
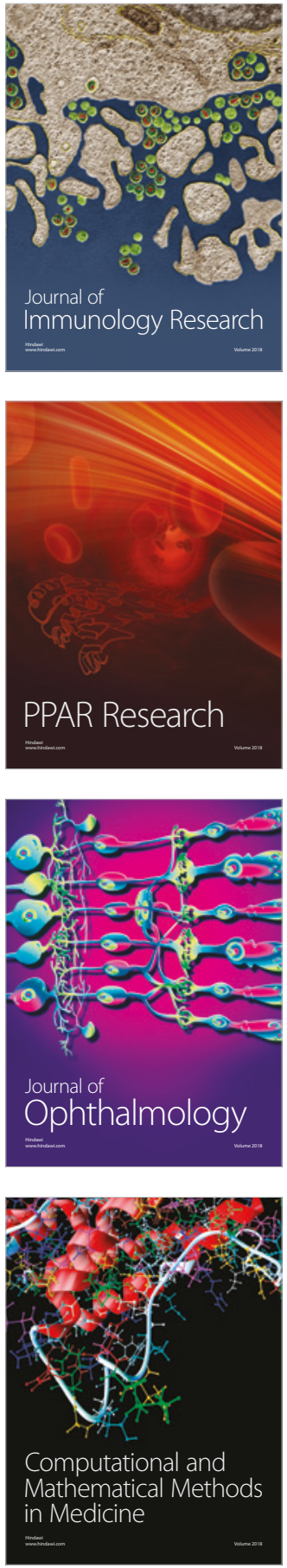

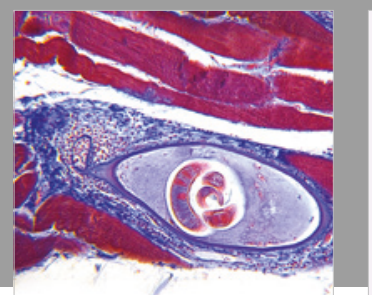

Gastroenterology Research and Practice

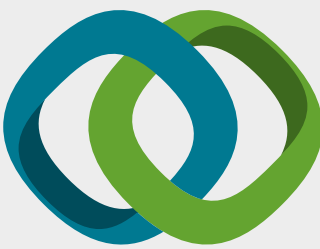

\section{Hindawi}

Submit your manuscripts at

www.hindawi.com
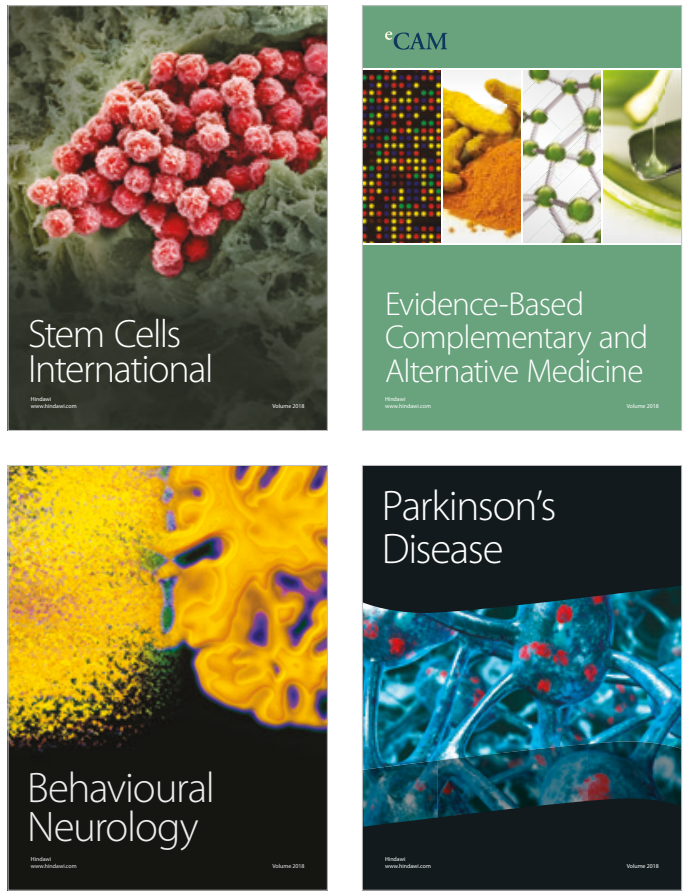

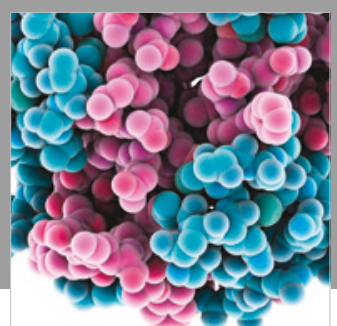

ournal of

Diabetes Research

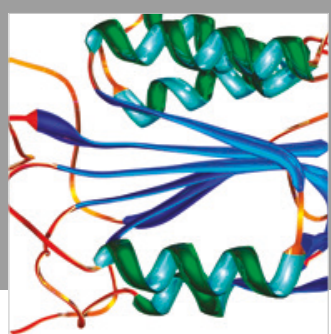

Disease Markers
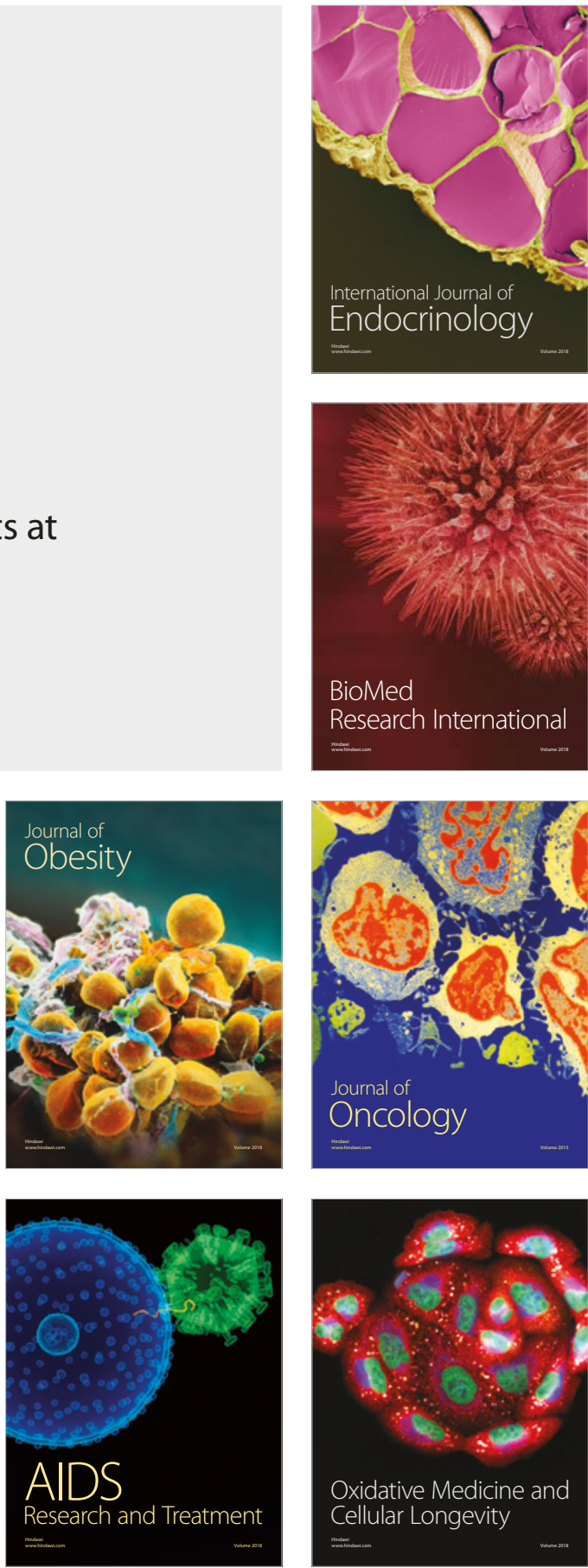